Portland State University

PDXScholar

Spring 7-11-2019

\title{
Closure or Censure? Examining the Determinants of Disclosure of Sexual Assault Among College Students
}

Whitney Head-Burgess

Portland State University

Follow this and additional works at: https://pdxscholar.library.pdx.edu/open_access_etds

Part of the Criminology Commons

Let us know how access to this document benefits you.

Recommended Citation

Head-Burgess, Whitney, "Closure or Censure? Examining the Determinants of Disclosure of Sexual Assault Among College Students" (2019). Dissertations and Theses. Paper 5111.

https://doi.org/10.15760/etd.6989

This Thesis is brought to you for free and open access. It has been accepted for inclusion in Dissertations and Theses by an authorized administrator of PDXScholar. Please contact us if we can make this document more accessible: pdxscholar@pdx.edu. 


\title{
Closure or Censure?:
}

Examining the Determinants of Disclosure of Sexual Assault Among College Students

$$
\text { by }
$$

\author{
Whitney Head-Burgess
}

A thesis submitted in partial fulfillment of the requirements for the degree of

\author{
Master of Arts \\ in \\ Sociology
}

Thesis Committee:

Matthew Carlson, Chair

Melissa Thompson

Aaron Roussell

\section{Portland State University 2019}


(C) 2019 Whitney Head-Burgess 


\begin{abstract}
Sexual assault is an ongoing problem on college campuses, with some projections indicating that one in four college women has experienced some sexual coercion or assault during her time at university. Recent national policy has strove to address the problem through legislation like the 2013 Campus Sexual Violence Elimination Act. Nonetheless, the crime remains the most underreported in the nation despite policy and law which explicitly defines what constitutes sexual assault. However, most victims of sexual assault will disclose what happened to someone else, even if they choose not to report.
\end{abstract}

This research examines sexual assault disclosure practices on a college campus which has taken a progressive stance on sexual assault awareness, response, and reporting. The purpose of the research was to examine the determinants of disclosure of sexual assault among a college student population. Students $(\mathrm{N}=161)$ at a mid-sized, liberal arts university on the west coast lacking both a Greek system and popular athletics were surveyed. Previous research has pointed to Greek life on campus and popular athletics as being catalysts for sexual assault. Based upon Koss's Sexual Experiences Survey, a 32-item questionnaire, distributed in May of 2015, was used to gauge student sexual victimization, alcohol and recreational drug use, and the situational factors surrounding the students' most recent incidence of assault or coercion. Responses to these situational and victimization questions were then used to explore the circumstances surrounding whether a participant disclosed their assault. 
Multivariate logistic regression was utilized to examine the predictors of disclosure of sexual assault. Significant determinants of disclosure included gender identification, relationship to the perpetrator, and a history of drug and alcohol incapacitated rape. Analyses showed that male identified individuals were less likely to disclose an instance of sexual assault; this was also true for those who experienced assault at the hands of a significant other or date. Further, a history of having been deliberately given drugs or alcohol to facilitate non-consensual intercourse was a significant predictor for disclosure.

This research was intended to fill the gap in the literature by focusing specifically on the determinants of sexual assault disclosure on a campus without a Greek system or a large, popular athletics program. Seeking to better understand the disclosure practices of students on such a campus, this research sought to closely examine the circumstances surrounding student sexual assault and how they interacted with the probability of disclosure. Implications for policy and practice regarding sexual assault prevention education on college campuses was discussed. 


\section{Acknowledgments}

Throughout the writing of this thesis I have received a great deal of support and assistance. I would first like to thank my thesis chair, Matthew Carlson, Interim Dean, College of Liberal Arts and Sciences, Portland State University, whose valuable and constructive suggestions helped guide this project to completion. His willingness to give his time so generously has been very much appreciated.

I would also like to acknowledge my deepest gratitude to Melissa Thompson of the Sociology Department at Portland State University, for her patient guidance, enthusiastic encouragement, and useful critiques of this work. She made herself available to answer questions and give advice and insight whenever it was needed.

Finally, I must express my very profound gratitude to my parents, Frank and Mary Head who provided me with unfailing support and continuous encouragement throughout this arduous research and writing process. Further, I would like to thank Christie Burgess for inspiring me to embark on this journey, and the friends too numerous to list whose love and support sustained me. This accomplishment would not have been possible without them. My sincerest thanks.

Whitney Head-Burgess 


\section{Table of Contents}

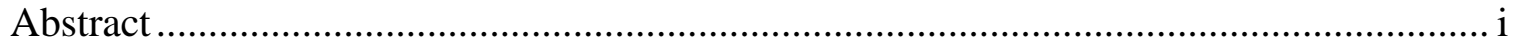

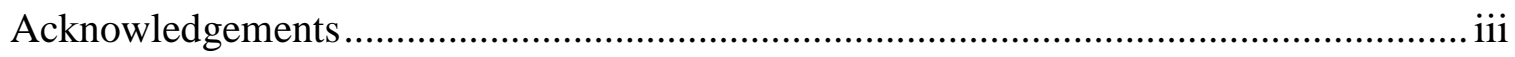

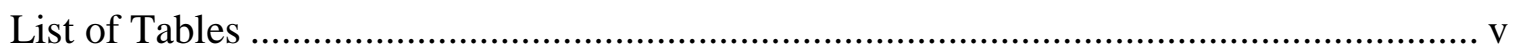

\section{Chapter 1}

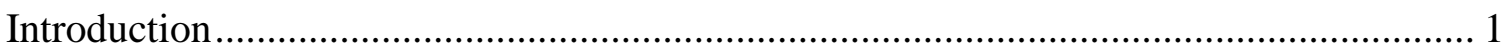

Chapter 2

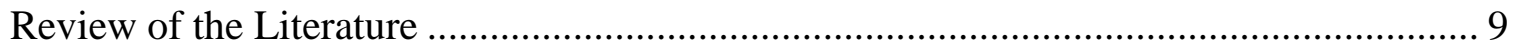

Chapter 3

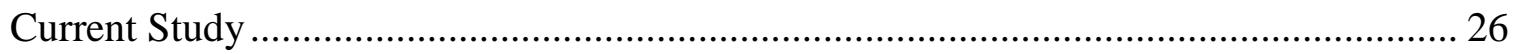

Chapter 4

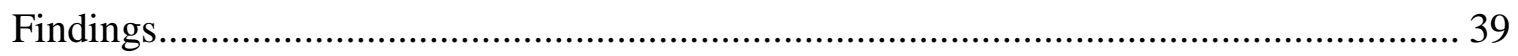

Chapter 5

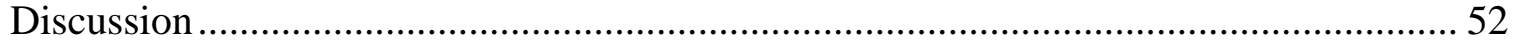

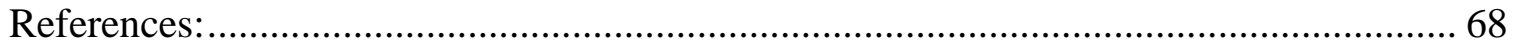

Appendix A: Informed Consent ........................................................................... 79

Appendix B: Survey Introduction........................................................................... 82

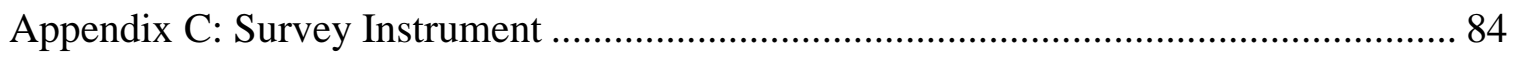

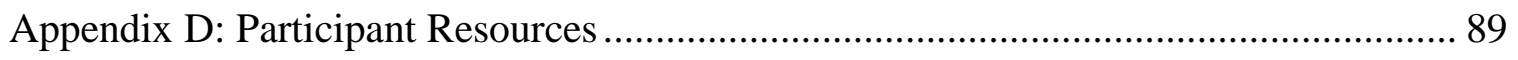

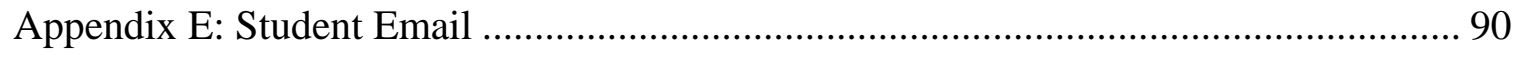




\section{List of Tables}

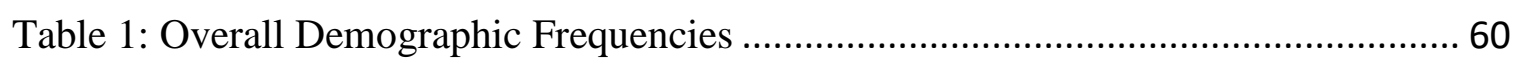

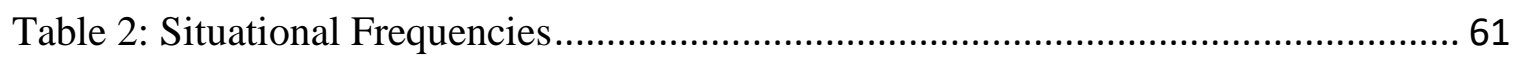

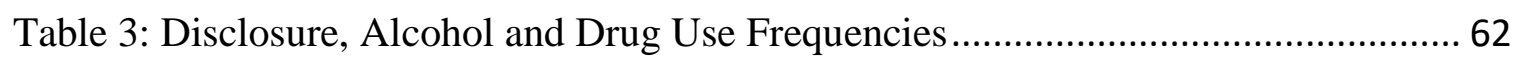

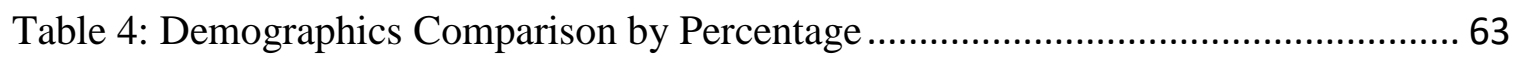

Table 5: Crosstabulation of respondents' disclosures by percentage ............................. 64

Table 6: Logistic Regression Models Predicting Disclosure of Sexual Assault............... 66

Table 7: Nested Logistic Regression Models Predicting Disclosure of Sexual Assault... 67 


\section{CHAPTER 1}

\section{INTRODUCTION}

The ubiquity of sexual assault on college campuses can hardly be argued. The 2017 rollback of Obama-era protections within Title IX have brought the issue into the realm of popular media and thus to the forefront of the American consciousness (Smith 2018; Suk Gersen 2017; Tolentino 2018). The problem has revealed itself to be widespread, with some projections indicating that one in four college women will experience some kind of sexual assault or sexual coercion during her time at university (Streng and Kamimura 2017; Wolitzky-Taylor et al. 2011). While colleges and universities have been actively policing and implementing policy regarding rape and sexual assault for over two decades, they still remain highly underreported crimes whose reported rates have not declined in the last fifty years (Armstrong, Hamilton, and Sweeney 2006). It is estimated that a vast number of sexual assaults go unreported, with a projected 80 percent being classified as date or acquaintance rape (Burnett et al. 2009). Moreover, at least partially because most sexual assaults on college campuses are generally perpetrated by someone known to the victim, formal reporting remains staggeringly low, between 5 and 33 percent (Paul et al. 2013). High rates of rape prevalent on college campuses has been linked to a culture which normalizes sexual assault, particularly acquaintance rape; moreover, the pervasiveness of party-culture, hook-up culture, and binge drinking have been shown to play a part in rape normalization (Armstrong et al. 2006; Banyard et al. 2005, 2007; Burt 1980; Deming et al. 2013; William F Flack et al. 2007; Jozkowski and Wiersma-Mosley 2017; Littleton and Axsom 2003; Moore 2014; Schwartz and Nogrady 1996; Sutton and Simons 2014). 
The literature suggests that over 70 percent of women who experience sexual assault disclose their victimization to someone close to them regardless of whether the event is ever reported to law enforcement officials (Krebs et al. 2007). This research examines sexual assault and disclosure practices on a college campus which has taken a progressive stance on sexual assault awareness, response, and reporting. Taking into consideration the subject university's climate of diversity, acceptance and progressive views regarding sexuality and sexual assault, this research examines sexual assault, unwanted sex, and the contributing factors surrounding student sexual assault and disclosure practices among undergraduates. This research was intended to fill the gap in the literature by focusing specifically on the determinants of sexual assault disclosure on a campus without a Greek system or a large, popular athletics program. Seeking to better understand the disclosure practices of students on such a campus, this research sought to closely examine the circumstances surrounding student sexual assault and how they interacted with the probability of disclosure.

\section{Defining Sexual Assault}

How federal, state, and university entities define rape and sexual assault is important to consider, since the definition of the crime can impact whether a victim labels their experience as assault or something less serious (Bierie and Davis-Siegel 2015; Johnson 1980). Official definitions of the crime impact how federal, state, and local funds are allocated to training and programs to combat sexual assault (Bierie and Davis-Siegel 2015).

The Federal Bureau of Investigations (FBI) reports that 200,646 instances of sexual assault took place in the United States in 2014 (FBI 2017). However, according to 
the National Crimes Victims Survey (NCVS) administered by the Bureau of Justice Statistics, 323,450 sexual assaults occurred in the same year (Morgan and Kena 2017). The difference between these two figures is due in large part to the definitional and methodological differences between the Uniform Crime Report (UCR) and the NCVS.

In 2013 the FBI redefined rape, removing the term 'forcible' and defining it as: "Penetration, no matter how slight, of the vagina or anus with any body part or object, or oral penetration by a sex organ of another person, without the consent of the victim" (U.S. Federal Bureau of Investigation 2013); included within this definition is attempted rape. The 2013 Crime Report included rapes which were defined by the previous definition (legacy definition) and the new definition (U.S. Federal Bureau of Investigation 2013). Within the data, these two definitions were examined and reported separately. UCR data on rape is compiled by the FBI by examining reports submitted by local, state, and federal policing agencies. Therefore, only reported rapes are recorded by the UCR. In contrast, the NCVS compiles data through qualitative interviews within the homes of victims, querying them about their victimization regardless of reporting to formal authorities. The NCVS examines not only occurrences of rape and attempted rape, but also incidences of sexual assault which they define as: "A wide range of victimizations, separate from rape or attempted rape. These crimes include attacks or attempted attacks generally involving unwanted sexual contact between victim and offender. Sexual assaults may or may not involve force and include such things as grabbing or fondling" (Bureau of Justice Statistics 2014). Victimization studies, such as the NCVS, often give a clearer picture to the actual number of sexual assaults and rapes 
which take place in this country since they take into consideration those instances of sexual assault not reported to the police or other officials.

Oregon law defines sexual assault as any unwanted sexual contact, and the official definition encompasses much more that the traditional, cultural understanding of rape. Oregon defines sexual assault as obtaining sexual contact through "forcible compulsion...[meaning] to compel by (a) physical force; or (b) a threat, express or implied, that places a person in fear of immediate or future death or physical injury to self or another person, or in fear that the person or another person will immediately or in the future be kidnapped" (Oregon State Law 2011). Further, the law takes into consideration mental and physical incapacitation including incapacitation caused by alcohol or drugs, which would impede a person's ability to relay messages of explicit consent.

For the purposes of this study it is also important to examine the definitions of sexual assault outlined by the Oregon University System. These definitions are as follows:

"Sexual misconduct" is any sexual contact or sexual behavior that is nonconsensual, inflicted upon someone who is incapacitated or forced. "Sexual contact" means the touching of the genitals, anus, buttocks, breasts or mouth, as well as any contact for the purpose of sexual gratification.

"Sexual behavior" means any action, short of sexual contact, done for purposes of sexual gratification and may include, but is not limited to, voyeurism, exposing, masturbation, sexually explicit audio/video recording, exploitation, or stalking. "Consent" is defined as shared sexual permission. Shared sexual permission is voluntary, non-coerced and clearly indicates a willingness to participate in sexual contact or sexual behavior, whether through affirmative verbal responses or non-verbal communication unmistakable in meaning and given by an adult aged eighteen years or older. Shared sexual permission for one form of sexual contact or sexual behavior does not operate as permission to any other form of sexual contact or sexual behavior. 
"Incapacitation" is a mental or physical condition that renders a person unable to grant consent. Incapacitation may be a state or condition resulting from the use of alcohol or other drug, lack of sleep, or unconsciousness. Incapacitation may also be the result of a cognitive impairment, a developmental disability, brain injury, or mental illness. "Force" includes, but is not limited to, physical force, violence, abuse, threat of force (direct or implied), intimidation, extortion, harassment, coercion, fraud, duress, or pressure.

(Oregon University System n.d.)

\section{Sexual Assault in Higher Education}

From the highly publicized case at Vanderbilt, to the activism protesting Columbia's handling of a rape case, sexual assault on college campuses has dominated the headlines and brought the issue to the foreground of the mainstream media (Barchenger and Garrison 2015; Forde 2014), leading to intense discussion regarding student safety and consent on university campuses nationwide. Title IX and the Clery Act have been reexamined regarding sexual assault and many universities have begun to adopt policies which require professors and university staff to be mandatory reporters of sexual assault (Association of Title IX. Administrators 2013). The 2013 amendment to the Higher Education Act of 1965 further requires colleges and universities receiving federal funds to define their policies regarding sexual assault reporting, procedures, and educational programming (Cox 2018; Maloney and Casey 2013).

Discussions regarding the nature of consent have also been highlighted in mainstream media. California's Senate Bill 967, also known as the 'Yes Means Yes' law is the first of its kind to regulate, stipulate, and mandate a uniform code for consent regarding sexual conduct, requiring those engaging in sexual activity to unambiguously consent (California State Law 2014; DeMatteo et al. 2015). While Senate Bill 967 applies 
to all citizens on and off college campuses, legislation has been implemented nationwide to protect and monitor violence on campus. The Jeanette Clery Disclosure of Campus Security Policy and Campus Crime Statistics Act of 1990 requires universities to annually disclose information about crimes committed on campus; the law was further amended in 1992 requiring colleges to develop sexual assault prevention policies (DeMatteo et al. 2015; Iverson 2016). The 2013 Violence Against Women Act, and the 2013 amendment to Title IX, entitled the Campus Sexual Violence Elimination Act, included portions targeting sexual violence on college campuses and expanded requirements on university campuses surrounding sexual violence awareness and disclosure of disciplinary proceedings following allegations of sexual assault (Cox 2018; Public Law 113-4 2013). However, of the 80 percent of universities who submit the annual report, only 37 percent report campus crime statistics in a manner fully compliant with Clery Act requirements (DeMatteo et al. 2015; Wiersma-Mosley and DiLoreto 2018; Yung 2015).

Title IX of the Educational Amendments of 1972 prohibits sexual discrimination in educational programs; this decree also includes sexual harassment and sexual violence as they interfere with a student's right to education (Ali 2011; DeMatteo et al. 2015; McCray 2015; The White House Task Force to Protect Students From Sexual Assault 2014; Wiersma-Mosley and DiLoreto 2018). The Dear Colleague letter issued in 2011 by the Obama White House outlined how Title IX can be used to combat sexual violence and called for institutions of higher learning to investigate, sanction, and adjudicate those who perpetrate sexual assault on college campuses (Ali 2011; Cox 2018; McCray 2015). This application of Title IX is grounded in the assertion that sexual assault interferes with 
a female student's access to equal education by creating an antagonistic learning environment (DeMatteo et al. 2015; Wiersma-Mosley and DiLoreto 2018). In 2014 the White House Task Force to Protect Students from Sexual Assault issued its first report, stating that the Department of Education's Office for Civil Rights had released a 52-point guidance document which clarified students' rights to protection and support from their institutions and elucidated Title IX protections in unambiguous terms (The White House Task Force to Protect Students From Sexual Assault 2014).

Sexual assault cases involving college students are often adjudicated on college campuses before a campus review board. In this disciplinary context, the burden of proof is much lower, administrative resolution can provide a victim better support from the academic institution; however perceived punishments for the perpetrators are less severe when sexual assault cases are handled by the university and said reprimands do not result in incarceration, leaving the perpetrator free to offend again (Cox 2018; DeMatteo et al. 2015; Krakauer 2015; Wiersma-Mosley and DiLoreto 2018). In some cases, the perpetrator is expelled from one institution only to re-enroll and offend again at another (Krakauer 2015). Moreover, offenders often remain unsanctioned, with only an estimated one percent receiving any disciplinary action at all (DeMatteo et al. 2015). While the discussion surrounding consent and sexual assault on college campuses is meaningful and progressive, there remains a disconnect between the letter of law regarding rape and sexual assault and how rape and sexual assault are viewed culturally. Many institution's policies are unclear regarding how the system works, to whom survivors are to report their victimization to, and follow-up care during the process; additionally, distrust in 
institutional response leads many victims to believe that the system is working against their interests (Banyard et al. 2005; Fisher et al. 2000; The White House Task Force to Protect Students From Sexual Assault 2014).

Despite state laws and explicit university codes of conduct defining what constitutes rape and sexual assault, many students, administrators, and criminal justice professionals maintain a culturally constructed idea of what constitutes 'real rape' (Bannon, Brosi, and Foubert 2013; Burt and Albin 1981; Carroll et al. 2016; Cleere and Lynn 2013; Deming et al. 2013; Hockett, Saucier, and Badke 2016; Ryan 2011). This cultural construct posits that in order for a sexual assault to be considered "real" it must be perpetrated by a stranger, with a high degree of violence (Bannon, Brosi, Foubert, et al. 2013; van der Bruggen and Grubb 2014; Burt 1980; Lindquist et al. 2009; Peterson and Muehlenhard 2004). However, 96 percent of sexual assaults on college campuses are perpetrated by persons know to the victim, usually within a party-type situation when one or both parties have been drinking (Armstrong et al. 2006; Banyard et al. 2005, 2007; Guerette and Caron 2008; Peterson and Muehlenhard 2004; Reling et al. 2017; Sims, Noel, and Maisto 2007). Previous research suggests that high levels of psychological coercion are used in cases like this, and there is often very little physical evidence such as visible bruising after such an assault (van der Bruggen and Grubb 2014), often leading victims to believe that their reporting of their experiences will be met with skepticism if not outright disbelief (Bannon, Brosi, and Foubert 2013; Banyard et al. 2005, 2007; Burt and Albin 1981). 


\section{CHAPTER 2}

\section{REVIEW OF THE LITERATURE}

Campus Culture

Partying, namely alcohol consumption in large social groups, is acknowledged as an important part of college life; college partiers are expected to over-imbibe and have a good time (Armstrong et al. 2006; Jozkowski and Wiersma-Mosley 2017). However, many first and second year students fall below the legal drinking age and often seek out private venues where they can obtain alcohol and party (Armstrong et al. 2006; Sanday 2007). Jozkowski and Wiersma-Mosley (2017) assert that since partying is a dominant form of socialization on college campuses, fraternities can maintain control over the party scene by hosting parties where minors can attend and imbibe. College policy limiting or banishing alcohol on-campus has had the effect of moving student partying off-campus; this suggests that fraternities are often the most reliable source for college students to obtain alcohol and engage in college partying (Armstrong et al. 2006). Armstrong et al. (2006) found that almost all underage students in their study went off campus to drink, since the bar scene was off limits to them and university policy did not allow for drinking in dorms or other university buildings. Organizational arrangements which promote a sexually dangerous climate for college women include rules about drinking and enforcement of the state drinking laws, and when drinking on campus is heavily sanctioned women are less likely to report especially if they are under the legal drinking age (Armstrong et al. 2006). Moreover, fraternities are often the sites for the college party scene; they tend to have the most permissive rules regarding alcohol consumption and underage students are more likely to be served at these functions (Armstrong et al. 2006; 
Jozkowski and Wiersma-Mosley 2017; Sanday 2007). As a result, young women often attend parties at fraternities since drinking in those locales often goes unpunished (Armstrong et al. 2006; Sanday 2007). This is further compounded by the university's lack of authority over fraternity houses, who often answer only to their national organizations (Armstrong et al. 2006; Boyle 2015).

Greek presence on college campuses is large, often seeming much larger because of the many fraternity houses on or in close proximity to many college campuses, and the rates of student engagement in fraternity activities, with some campuses reaching 80 percent participation rates (Jozkowski and Wiersma-Mosley 2017: 91). Moreover, their presence is keenly felt in student life because of visibility, fraternities in particular often sponsor activities where their members are highly visible on campus, recruiting new members, promoting parties, and sponsoring social events (Jozkowski and WiersmaMosley 2017). Research indicates that fraternities maintain control over who attends their parties, letting in young women and keeping unaffiliated men out (Armstrong et al. 2006; Jozkowski and Wiersma-Mosley 2017). Armstrong et al. (2006) and Sanday (2007) argue that some fraternities actively target young women, plying them with strong alcoholic beverages and creating an atmosphere which is highly sexualized (Armstrong et al. 2006; Jozkowski and Wiersma-Mosley 2017; Martin 2016; Sanday 2007). Sexual assault most often occurs in this atmosphere of young, single people concerned with drinking and social status (Armstrong et al. 2006).

Research has pointed to homogenous male spaces as being places where acquaintance rape is more likely to occur, namely parties involving fraternities (Sanday, 2007; Armstrong, Hamilton, \& Sweeney, 2006). Martin (2016) suggests that social 
contexts such as these create rape-prone spaces; the dynamics of the fraternity party scene can more easily facilitate a coercive sexual atmosphere and make them more probable sites for sexual assault. Jozkowski and Wiersma-Mosley (2017) echo this assertion, arguing that fraternities often produce sexually aggressive behavior and foster a subculture of misogyny. The ethos within the all-male spaces of fraternities often hold an exaggerated view of masculinity, this hypermasculinity results in a culture which views women as sexual adversaries (Bannon, Brosi, and Foubert 2013; Boyle 2015; Edwards, Bradshaw, and Hinsz 2014; Jozkowski and Wiersma-Mosley 2017; Sanday 2007). This finding is echoed by Boyle (2015) who contends that while alcohol may be a predictive factor for sexual assault, some fraternities actively create a social environment which facilitates such acts. Aligning with Sanday (2007) and Armstrong et al. (2006), Brubaker (2009) found that college campuses and military service academies can participate in a culture that is highly male dominated which results in a "culture of encouragement of demeaning views of women and acceptance of sexual assault" (p. 64). In contrast to Sanday's (2007) findings, Schwartz and Nogrady (1996) argue that alcohol, rather than just the presence of male dominated spaces, such as fraternities, was a more reliable predictive factor of sexual assault. Further, they found that while sexual aggression has a statistically significant relationship to fraternities that relationship became non-significant when alcohol consumption was added to the model.

\section{Hook-up Culture}

Hooking-up has become a large part of campus culture and is important in understanding campus culture and the ubiquity of sexual assault in this context. The 
literature defines 'hooking-up' as a casual sexual encounter between two non-dating people with the stated and/or recognized assumption that a committed relationship will not ensue (Downing-Matibag and Geisinger 2009; Heldman and Wade 2010; Kalish and Kimmel 2011; Lambert, Kahn, and Apple 2003; Littleton et al. 2009; Menegatos, Lederman, and Hess 2010; Moore 2014). Large numbers of college students admit to having engaged in hook-ups, with some reports stating those numbers as high as 79 to 85 percent (Heldman and Wade 2010; Littleton et al. 2009). It is important to note that not all hook-ups end in sex; when asked, many college students stated that a hook-up can consist of kissing, fondling, petting, oral sex or sexual intercourse (Kalish and Kimmel 2011).

Kalish and Kimmel (2011) argue that hook-up culture benefits men predominantly, because sex of this type is used to boost men's sexual reputations and freeing them from the emotional attachments associated with relationships (pp. 138). This culture also allows women to act in the same way, however, the consequences of their actions are distinctly different from those of men. Namely, hooking up enhances the reputation of a man, while the same activities can damage the reputation of a woman (Heldman and Wade 2010; Kalish and Kimmel 2011; Moore 2014). Further, the research suggests that women's sexual experiences with the context of a hook-up are often deprioritized; this often results in unwanted and/or non-pleasurable sexual experiences (Heldman and Wade 2010; Kalish and Kimmel 2011; Moore 2014). Littleton et al. (2009) assert that sexual scripts regarding hook-ups suggest that men often go out in search of a hook-up that leads to intercourse, while women may have different expectations for 
hooking-up; such as kissing, petting or oral sex. This disconnect suggests that a fundamental difference in sexual expectancies occurs between men and women within the context of hook-up culture (Kalish and Kimmel 2011; Lambert et al. 2003). That is, men often believe women are more comfortable engaging in intercourse during a hook-up than they might actually be (Lambert et al. 2003).

Steeped in the cultural norm of college drinking, hook-ups are most often associated with high levels of alcohol consumption; college students often see alcohol as a 'social lubricant' which facilitates better social skills and, ultimately, sexual activity (Menegatos et al. 2010). Kalish and Kimmel (2011) suggest that hook-up culture exists solely within college party culture when both parties have been drinking. This is significant because high numbers, some research suggests up to 72 percent, of sexual assaults on campuses involve alcohol consumption (Littleton et al. 2009). Flack et al. (2007) argue that unwanted sex and unwanted sexual advances occur frequently within campus hook-up culture, but often are not labelled as sexual assault by the victims. This is a pervasive theme in the literature surrounding hook-ups and alcohol consumption; research suggests that often what is labeled a 'bad hook-up' meets the legal criteria for sexual assault (Flack et al. 2007; Littleton et al. 2009).

Littleton et al. (2009) argue that hook-up culture contains three distinct sexual scripts regarding a 'bad hook-up', these are "an alcohol-facilitated hook-up, hook-up as a result of manipulation, and date hook-up" (p. 798). While many of these bad hook-up scenarios met the legal definitions of sexual assault, the use of alcohol to facilitate unwanted sex has become so pervasive within college party culture that often the victims 
do not label what happened to them as a sexual assault but rather a misunderstanding, or simply bad sex (Littleton et al. 2009). Downing-Matibag and Geisinger (2009) argue that sexual coercion, within the context of hooking-up, occurs almost solely among women. Although most of these women acknowledge that this sex was unwanted, they decline to label it as sexual assault, even though they acknowledge that verbal coercion and/or the threat of physical force was used (Downing-Matibag and Geisinger 2009: 1203).

\section{Alcohol Expectancies}

Alcohol expectancies are defined as views about the positive and negative consequences of alcohol consumption (Benson, Gohm, and Gross 2007). Among women, alcohol expectancies can include the belief that drinking will help them relax, heighten their sexuality, and make social situations easier (Benson et al. 2007; Messman-Moore et al. 2008; Miranda et al. 2002). This means that women who believe that alcohol heightens their sexuality will be less likely to recognize the negative consequences of risky behavior while drinking, including being less likely to notice signs of sexual aggression in men (Benson et al. 2007:904). Among men, alcohol expectancies include a perceived increase in sexual prowess and heightened sexual aggression (Benson et al. 2007; Messman-Moore et al. 2008). These types of alcohol expectancies among men are often correlated with sexual assault and coercion, as men misread or ignore resistance cues.

Heavy alcohol use, like that often found in the college partying scene, has been shown to correlate with higher rates of sexual assault (Armstrong et al. 2006; Kaysen et al. 2006; Kilpatrick et al. 2007; Messman-Moore et al. 2008; Mohler-Kuo et al. 2004; 
Schwartz and Nogrady 1996). Kilpatrick et al. (2007) found that binge drinking and sexual assault occurred at much higher rates among college students than the general populace. For example, among college women who reported binge drinking at least once per month in the last year, 13 percent more women reported being the victim of forcible rape, 24 percent more reported experiencing a drug and alcohol facilitated rape, and 27 percent more reported being the victim of incapacitated rape (Kilpatrick et al. 2007:52). Further, due to the culture surrounding college drinking Sanday (2007) argues that alcohol is often used as a coercive tool by sexually aggressive men to get women to consent to sex. Increased alcohol consumption by men can predict perpetration of heightened levels of sexual aggression, a delayed reaction in identifying women's sexual refusals, and attention to the short-term rewards of aggression rather than the long term effects of an action (Benson et al. 2007; Mohler-Kuo et al. 2004; Untied, Orchowski, and Lazar 2013).

Indeed, alcohol consumption appears to be a leading predictor of sexual assault on campuses. Both Schwartz and Nogrady (1996) and Mohler-Kuo et al. (2004) found that alcohol consumption was a more reliable predictor of sexual assault than the presence of a Greek system on campus. Previous research had pointed to Greek systems on university campuses as being major contributors to campus sexual assault (Sanday 2007). Further, studies suggest that heavy alcohol use could predict occurrences of sexual assault among first-year university women; asserting that two mechanisms by which alcohol confers risk of sexual assault are as follows: increased drinking results in women being more exposed to motivated perpetrators, and engaging in drinking often casts women as suitable victims 
(Mouilso, Fischer, and Calhoun 2012:89). These studies suggest that the more alcohol a women consumes the greater the risks conferred by alcohol consumption are likely to be (Mohler-Kuo et al. 2004; Mouilso et al. 2012). Women who engaged in frequent, heavy drinking were found to be significantly more likely to have experienced sexual assault while intoxicated (Kilpatrick et al. 2007; Mohler-Kuo et al. 2004).

\section{Rape Myths}

Rape myths contribute to a culture of sexual violence and are defined as

detrimental, stereotypical, and inaccurate views about what constitutes rape, rape victims, and perpetrators (Burt 1998: 129); these myths often serve to reject or minimize the perceived injury to the victim, while blaming them for their own victimization (Burt 1980: 217). Schwartz and Nogrady (1996) suggest that an individual who adheres to rape myth ideologies is more likely to "differentiate between [what they perceive as] 'real rape' (see: stranger rape) [versus] 'other events"' that may nevertheless include what the victim, but not the perpetrator, view as coercive (p. 151). This environment is perpetuated by misconceptions about acquaintance rape and sexual assault that include minimizing the harm done to the victim and blaming her for her own assault (Burt 1980, 1991; Burt and Albin 1981; Donde et al. 2018; Hockett et al. 2016). Victim blaming and the distinction between 'real rape' and other forms of what the victim (but not the perpetrator) may view as coercive sex, results in the normalization of date and acquaintance rape as part of campus culture (Benson, Charlton, and Goodhart 1992; Burnett et al. 2009; Hayes, Abbott, and Cook 2016; Hockett et al. 2016; Sanday 1996, 2007; Schwartz and Nogrady 1996). When viewed through this lens, women are 
generally cast as the gatekeepers of sexuality and are expected to "shoulder the burden of sexual responsibility and successfully resist unwanted sexual contact" (Benson et al. 1992: 159). This type of rationale is rooted in the historical Anglo-European treatment of sexual assault victims and perpetrators (see Donat and D'Emilio 1992 for a description of this history).

Deming et al. (2013) argue that rape myths are not solely engaged in by males in campus culture. Their research found that women, often victims of sexual assault themselves, engage in the perpetuation of rape myths. The most common of these were to excuse the perpetrator for their behavior by blaming the victim, and accusing the victim for not leaving the situation or resisting the assault (Deming et al. 2013; McMahon 2007). Likewise, Sanday (2007) and McMahon (2007) found that college women often engage in blaming the victim for their own assault if the victim had been drinking at the time of the incident. Further, research suggests that while survey methodology may show that students have lower levels of rape myth acceptance, focus groups and interviews with student athletes revealed that rape myth acceptance among men and women was still very high (McMahon 2007). Similarly, Carroll et al. (2016) assert that the Greek system as a whole tends to hold rape myth supportive beliefs; their research indicated that not only do fraternity members ascribe to rape myths at higher levels than their non-Greek peers, but so do sorority women, though at lower levels than men (p. 8). Hayes, Abbott, and Cook (2016) found that reported drinking behavior positively influenced rape myth acceptance among college males. Moreover, membership in a peer group that encourages hostile masculinity, adversarial gender relations, and drinking was positively correlated to high levels of rape myth acceptance and attempted sexual assault (Hayes et al. 2016). 
Burnett et al. (2009) assert that rape myths are a social and cultural phenomenon which appear to be prolific in the male dominated areas of athletics and fraternities; they suggest this is results from the homogenous nature of men's athletics and fraternal organizations where men "often gain prestige from being physically dominating" ( $p$. 466). This suggests that these types of homogenous male cultures could contribute to the likelihood of sexual assault and subsequent under-reporting. Additionally, research suggests that rape culture "fosters silencing" (Burnett et al. 2009: 467) that translates to lower instances of reporting sexual assault to authorities. Alcohol appears to be a significant factor when examining sexual assault and the allocation of blame on the victim (Deming et al. 2013; Felson and Paré 2005; Fisher et al. 2003; Kahn et al. 2003; Koo et al. 2015; Littleton et al. 2006; Schwartz and Nogrady 1996). Disclosure of sexual assault

While attempted and completed rape affects an estimated 11.5 percent to 17.6 percent of women throughout the course of their lifetimes, estimates of reported rape to formal agencies, like law enforcement are astoundingly low, at between five and 33 percent (Paul et al. 2013). However, the research suggests that despite low official reporting, two-thirds up to 90 percent of victims disclose to a family member, friend, or romantic partner (Ahrens et al. 2007; Ahrens, Stansell, and Jennings 2010; Dunn, VailSmith, and Knight 1999; Littleton et al. 2006; Paul et al. 2013). However, as Moors and Webber (2012) point out, disclosing is not a single event, but is rather a continuum defined by uncertainty, questions regarding trust, and the subsequent consequences of the disclosure (p. 801). 
To disclose the victim must first make the decision that an incident has befallen them; this means an acknowledgement that unwanted intercourse or sexual assault has occurred (Ahrens et al. 2010; Allen, Ridgeway, and Swan 2015; Deming et al. 2013; Moors and Webber 2012). Allen, Ridgeway, and Swan (2015) assert that in order for disclosure to take place three components in the help-seeking process must be present: recognition and definition of the experience as problematic for the victim, a conscious decision to seek help must be made, and the selection of a particular type and source of support (p. 103). Once these three criteria have been met, a victim will often disclose their experience, more often to friends than to family members (Allen et al. 2015; Felson and Paré 2005; Fisher et al. 2003; Moore and Baker 2016; Moors and Webber 2012).

Deming et al. (2013) suggest that by disclosing their assault to others, victims "define their own experiences within the norms of their social groups" (p.467); norms which are often influenced by rape myths and misconceptions about the nature of what constitutes sexual assault. Sanday (2007) argues that the "causualization of sex" within the context of party culture often leaves women questioning whether their experiences at parties would qualify as sexual assault under the law. This ambiguity about whether a crime has been committed is problematic and many women assaulted at parties or after drinking fear that they will be blamed or ostracized for what happened to them, or worse, not be believed by those in authority, and therefore do not report their assault formally and often find this a barrier to disclose to others (Benson et al. 1992; Donde et al. 2018; Sable et al. 2006).

Many times a victim of sexual assault does not label their experience as such because it does not match the rape script they have internalized; instead these experiences 
are frequently labeled as miscommunications or seduction (Littleton et al. 2006; Zinzow and Thompson 2011). Additionally, those who may internally label their experiences as sexual assault, may not externally label it as such, given the cultural connotations surrounding sexual victimization and the negative societal views and perceptions surrounding victimhood of this kind (Donde et al. 2018). Whether a victim acknowledges and labels their experience as sexual assault appears, in some cases, to affect disclosure rates and the quality of reactions that a victim receives (Ahrens et al. 2007, 2010; Ahrens and Aldana 2012; Branch and Richards 2013; Dunn et al. 1999). Ahrens et al. (2007) posit that most, in their study two-thirds, of victims who disclosed received a positive reaction to their disclosure. Moreover, friends of victims appear to offer more salient support to victims than family members or romantic partners (Ahrens and Aldana 2012; Rickert, Wiemann, and Vaughan 2005).

Research has demonstrated that the closer the relationship is between the victim and the perpetrator, the less likely it becomes that the victim will report or even disclose the assault (Dunn et al. 1999; Felson and Paré 2005). Victims of rape, particularly date or acquaintance rape are more apt to disclose their victimization to a friend, rather than reporting it to law enforcement or telling their families (Dunn et al. 1999; Rickert et al. 2005; Sable et al. 2006; Wolitzky-Taylor et al. 2011). Further, victims of sexual assault often gauge their choice to disclose upon the perceived reactions they think they will receive; some disclosures are met with support, others with negativity (Ahrens 2006; Ahrens et al. 2007; Ahrens and Aldana 2012). Ahrens et al. (2010) found that those victims that disclose fall roughly into four groups: nondisclosures, or those who do not label their experience as assault; slow starters, those who wait long periods of time before 
disclosing; crisis disclosers, those who disclosed within the first week of the assault; and on-going disclosers, those who disclosed within the first week and continued to disclose (p.637). The time frame in which a victim discloses appears to influence whether they receive a positive or negative reaction to their disclosure (Ahrens and Aldana 2012). Additionally, to whom a victim discloses often effects the disclosure reaction; that is, those victims who waited longer to disclose received more negative reactions to their disclosures (Ahrens and Aldana 2012; Ahrens et al. 2010). Ahrens and Aldana (2010) found that victims described three different social reactions per disclosure, one of which was positive in nature.

Negative reactions to disclosure of sexual victimization can become a barrier to further disclosures (Ahrens 2006; Ahrens et al. 2007; Allen et al. 2015; Felson and Paré 2005). Moreover, feelings of shame, embarrassment, fear of recipient disbelief or blame, and self-blame are barriers which effect when victims disclose and to whom (Felson and Paré 2005; Fisher et al. 2000; Koo et al. 2015; Littleton et al. 2006; Moors and Webber 2012; Orchowski and Gidycz 2012, 2015). Orchowski and Gidycz (2015) assert that because victims will often disclose to friends or family members, negative reactions from those individuals have the potential to be more distressing, therefore anticipation of negative response can be a barrier to disclosure and any future disclosures of the incident. Koo, Nguyen, and Andrasik (2015) suggest that a victim may choose to not disclose if they feel that a disclosure would place too much stress upon their family. Likewise, Littleton et al. (2006) found that victims who acknowledged and disclosed their assaults to family members were associated with increased likelihood of receiving egocentric 
reactions for which they would have to provide support to the person to whom they disclosed.

\section{Theoretical Framework}

Investigating the circumstances surrounding college students' experiences of sexual assault and whether and to whom they disclosed to, Critical Feminist Theory can be used as a mechanism to explain the phenomena. When, where, and if victims disclose has much to do with the dominant discourses of sexual assault, what constitutes an 'actual rape', and the gender identities of both the victim and perpetrator. This theory informed the types of variables examined and can offer explanations as to why victims choose to react to sexual assault in the ways that they did and why they chose to disclose or remain silent.

Sexual assault is a systematic and pervasive problem rooted within the cultural ideals of patriarchy, giving certain members of society more privilege than others (Gannon and Davies 2007; Johnson 1997). The ubiquity of sexual assault can be seen as a result of the normalization of male dominance over women's bodies (Orchowski, Untied, and Gidycz 2013), and sexism as a social reality can explain much of the sexual assault issue, since "power tends to be seen within critical theory as oppressive and unilinear, and it is enacted by certain groups on other groups" (Gannon and Davies 2007: 77). Cultural beliefs positing that women are the sexual gatekeepers, and men are sexual predators are prevalent, and based in a "social reality that underpins male privilege" (Johnson 1997: 123). Moreover, Critical Feminist Theory can explain why survivors of sexual assault are so reticent to report the crime; the very structure of the culture and policy automatically bring into question the claims of the victim. Culturally they are 
silenced by adherence to rape myths and cultural ambiguity regarding what constitutes a "real" sexual assault. Structurally, victims are impeded by many of the same cultural biases which have worked their way into policy and how victims are treated should they decide to report or disclose (Iverson 2016; Paul et al. 2013). Victim shaming, and minimization of the harm done by assault are directly linked to the cultural ideas espoused by the patriarchal dominant discourse (Iverson 2016).

Critical Feminist Theory posits that "feminist accounts derive their justificatory force from their capacity to illuminate existing social relations" (Hawkesworth 1989: 557) and recognize prevailing social structures that support the dominant discourse surrounding sexual assault and its victims (Wood 2008). Further, the theoretical paradigm examines how cultural structures shape the understandings and experiences of those within that culture, particularly among those who are subordinated, or through the actions of others put in a subordinate position. This theoretical lens explores how members of a culture influence and shape their cultural practices and structures (Wood 2008). More specifically, Critical Feminist Theory is interested in how formal and informal means of power are employed by one segment of the population in order to control or channel the actions and words of another. Within the context of this research, this means using Critical Feminist Theory to examine the types of power dynamics victims of sexual assault encounter and how those shape whom they disclose to, if they disclose at all.

In the case of assault, power inheres in formal structures of reporting that follow official policies put in place by the university concerning sexual misconduct, or state laws regarding rape and other forms of sexual assault. This can be evidenced in new regulations regarding Title IX handling of sexual assaults on college campuses; here 
secretary of education DeVos implemented changes to the existing regulations, effectively making it more difficult for victims to be acknowledged or heard (Brown and Mangan 2018). Within this context, structural power which already favors the dominant group, reinforces their power over the subordinated by allowing rules to be put in place making it harder for victims to come forward in an official capacity to report their victimization; specifically, the perpetrator's new right to cross examine the victim has the potential to deter disclosure and reporting (Brown and Mangan 2018; Cox 2018; Wiersma-Mosley and DiLoreto 2018). Moreover, power inheres in the structure of the regulations themselves, which narrow the definitions of what can be considered sexual assault and therefore adjudicated within the university disciplinary system (Brown and Mangan 2018; Wiersma-Mosley and DiLoreto 2018).

Power also exists in informal structures which manifest themselves in the everyday interactions members of a culture engage in. This can be seen within the rubric of rape myths and sexual scripts which posit that a female victim is responsible for her own victimization and a male victim cannot actually be victimized by virtue of his gender (van der Bruggen and Grubb 2014; Harber, Podolski, and Williams 2015; Hayes et al. 2016; Ryan 2011; Sable et al. 2006). These narratives undermine victims' authority over their own victimization, narrating their understanding, and placing judgement upon their experiences thus keeping them in a silenced and subordinated position (Marcus 1992).

By examining these interconnected power structures and how they inform and constrain victims of sexual assault, it becomes clear how dominant culture influences disclosure practices. Because often women, people of color, and sexual minorities are underrepresented in dominant culture and within both formal and informal power 
structures, their experiences are often "less acknowledged and valued, less available for reference, and less open to challenge and negotiation" (Wood, 2008: 329). Examining differential power dynamics between the dominant culture, in this case a campus culture which blames victims for the circumstances of their own assaults, and victims of sexual assault, a greater understanding of disclosure can be obtained. 


\section{CHAPTER 3}

\section{CURRENT STUDY}

This study sought to extend the literature regarding determinants of disclosure of sexual assault among college students by examining the experiences of students attending classes on a campus with no Greek system, and a sports program which is not nationally, or even regionally renowned. Until now, most research in this area has centered upon campuses with popular athletics, fraternities, and sororities. Moreover, previous literature has almost exclusively focused upon the disclosure practices of college women; this study endeavored to look at the experiences of male and female identified students, as well as those identifying as non-binary.

\section{METHODOLOGY}

Site Selection

Based upon Merton's concept of the strategic research site, Southern Oregon University (SOU) was chosen as an optimum site for conducting the enquiry (Merton 1987). That is, the university population lends itself particularly well to examining the research questions (Holton 2004), because it is a midsized, public, liberal arts college which does not have a Greek system, nor a large athletics department. Prior research indicated that fraternity/sorority systems and popular athletics can foster an environment of male dominated space and a more normalized acceptance of sexual violence (Armstrong et al. 2006; Brubaker 2009; Jozkowski and Wiersma-Mosley 2017; Sanday 1996, 2007). The research adds to the literature by examining determinants of sexual assault and sexual violence disclosure; investigating the patterns of disclosure on a campus which lacks both a Greek system and large athletics department. Moreover, by 
allowing for men, women, and those identifying as non-binary to relate their experiences the survey broadened the lens on gender, sexual assault, and disclosure.

The research was conducted in partnership with the Women's Resource Center at Southern Oregon University. The campus was selected because of its demographics; approximately 70 percent of its students are Oregon residents, and nearly 60 percent are first-generation college students. The university is not particularly ethnically diverse, however what it lacks in ethnic and racial diversity it makes up for in diversity of student experience. Students at Southern Oregon University are overwhelmingly non-traditional students from varied socio-economic backgrounds. The demographic makeup of the student population is interesting in that there is a high percentage of non-traditional and first-generation students, which is a population not addressed in the literature. The campus houses only 30 percent of its students on campus, and has no Greek system (Southern Oregon University 2014). Additionally, Southern Oregon University is highly diverse with regard to sexual orientation and gender expression. The campus boasts active Queer and Women's Resource Centers, both of which dynamically advocate for sexual education and sexual assault awareness. Separate institutional review board approval was sought and granted for both Portland State University and Southern Oregon University for the project.

Participant Selection

The target population for this study was the undergraduate student body of Southern Oregon University over the age of 18. In May of 2015 the student population at the university was 4,376 undergraduate and graduate students and these students were accessed through a partnership with the Southern Oregon University Women's Resource 
Center (Southern Oregon University 2016). Of this population 58.2 percent of students identified as female, 39.4 percent identified as male (Southern Oregon University 2016). The population consisted of undergraduate students attending classes on campus, as well as those who attended the university via an online platform. Over half (55.7 percent) of the students attending Southern Oregon University were in-state students, with the remainder of students from out of state or international (Southern Oregon University 2016). An email sent through the Women's Resource Center listserv targeted all SOU students; participation in the survey was voluntary, and mechanisms were put in place within the survey instrument to ensure only undergraduate students could participate. Research Questions

Drawing on Critical Feminist Theory, this study strove to better understand the determinants of disclosure of sexual violence. The research examined the circumstances surrounding the assault, specifically the relationships the victim had with the perpetrator, the place of occurrence, and the events leading up to the assault. These are important to consider, because this research centers on a campus which lacked many of the patriarchal power structures often found in previous research, namely fraternities and popular athletics. Drug and alcohol consumption, and the victims' experiences with disclosure to others were also examined. The purpose of this study was to better understand determinants of disclosure of a sexual assault or instance of sexual coercion, the main research questions were as follows:

a. What factors affect sexual assault disclosure?

b. How do gender, age, and relationship to the perpetrator affect disclosure practices? 


\section{Hypotheses}

Based upon the literature surrounding sexual assault on college campuses and disclosure, several hypotheses were put forth regarding what would be revealed by the survey data. Hypothesizing that gender identification would influence sexual assault, it was hypothesized that those who identify as male would be less likely to tell anyone about their victimization. Further, the circumstances surrounding the sexual assault will influence disclosure among victims. Hypothesizing that those victims in close relationships with their assailants would be less likely to disclose was guided by previous research showing the negative association between disclosure and a dating relationship with the perpetrator. Higher levels of non-disclosure were hypothesized among younger students, given the literature surrounding age and likelihood of sexual assault within the first two years of university attendance. Place of incidence was also put forth in the literature as being a predictor of sexual assault; it was hypothesized that those students reporting that the assault occurred in their own homes would be more likely to disclose, while those reporting the incident took place in the perpetrator's domicile would be less likely to disclose.

\section{Data Collection}

The data on sexual assault, unwanted sex, alcohol consumption, and disclosure were obtained through a thirty-two-item survey which was based upon Koss's Sexual Experiences Survey, a research instrument first utilized in 1980 to gauge the varying degrees of sexual victimization among women (Koss and Oros 1982). This survey is one of the most widely used measures of sexual victimization and uses behaviorally specific questions to assess victimization (Zinzow and Thompson 2011). Core questions 
regarding sexual experiences, coercion, and sexual assault from Koss's (1982) Sexual Experiences Survey were used to measure sexual victimization. White, Smith, and Humphrey's 2001 research addressing alcohol consumption, gender role adherence, and interpersonal violence victimization was utilized for questions regarding the circumstances surrounding victimization (White, Smith, and Humphrey 2001). Question wording from both research instruments was not altered significantly, but was gender neutralized in hopes of revealing sexual victimization among women, men, and those identifying as non-binary. Additionally, demographics questions regarding sexual identity and gender expression were added.

This project used online survey methodology to examine student's experiences of sexual assault and disclosure as Southern Oregon University students. The researcher obtained IRB approval through Portland State University (PSU) to conduct the research, and a second approval through SOU to administer the survey.

The Southern Oregon University Women's Resource Center collaborated on the survey and acted as a sponsor and partner for the research; their listserv of SOU students was utilized in order to inform students of the upcoming survey and to distribute the survey, which was administered electronically via Qualtrics survey software through Portland State University in May of 2015. Participants were asked to electronically sign the informed consent to participate. For the purposes of this study, the survey was sent via solicitation e-mail to all students currently enrolled at Southern Oregon University in order to maximize the response numbers, with a mechanism in place to record responses from undergraduate students only. At the time of survey launch, it is likely that the solicitation email reached the 4,376 students currently enrolled at Southern Oregon 
University, of which 3,977 were eligible to participate in the research due to class standing. Appendix E contains the solicitation email which outlined the project as wanting to examine student experiences with consensual sex, unwanted sex, and sexual assault. The email was worded in this way to engage the greatest number of students in the survey. The literature suggests that many students experience what meets the legal definitions of sexual assault but fail to label it as such; the solicitation email and survey were thus structured to include questions about consensual sex, consensual unwanted sex, and sexual assault to potentially engage those who may not have labeled such an encounter as an assault (Littleton et al. 2009). Email and participant interfaces were structured in such a way that students answered the survey anonymously.

Participants were asked to read and electronically sign an informed consent to access the survey which can be found in Appendix A. The second page answered questions about the survey, outlined the research, let the participants know what to expect from the survey instrument, and also informed respondents that they were free to withdraw from the survey at any time without penalty; a full text of this can be found in Appendix B. Southern Oregon University Women's Resource Center provided the names and numbers of mental health and trauma counselors, and hotline numbers should participants want to talk about their experiences or found themselves triggered by participation in the survey. Full text of the survey instrument and resources provided to the students can be found in Appendices C and D. Data collection was approximately two weeks in May 2015 with an overall response of 393, 7.7 percent of the student population. 
The survey was structured to protect student anonymity, no questions were asked that could identify participants. Participant IP addresses were scrubbed prior to analysis, further insuring respondent anonymity. Respondents were informed of these privacy measures on the survey introduction page in Appendix B.

Data Analysis

The data were analyzed utilizing SPSS statistical software, version 22. Descriptive statistics were presented as frequencies and percentages for categorical variables and in the case of one continuous variable, as a mean and standard deviation (SD). Multivariable multiple regression analyses were conducted to predict student disclosure of sexual assault based upon student age, class standing, gender identification, drinking habits, personal and perpetrator drinking at the time of assault, place of the assault, and whether the student had ever attended a sexual assault prevention class. Because of the survey structure, all surveys were utilized in the analyses; however, not every participant indicated they had been victimized. Of the original 3,977 students eligible to participate in the survey, 393 students responded; of those, 161 students answered the question, "whom did you tell?". These 161 students became the analytic sample for the research.

\section{Dependent Variable}

The dependent variable for this research was whether the respondent disclosed their sexual assault to anyone. The answer to this question stemmed from previous questions in the survey in which respondents were asked if they had been sexually coerced or assaulted within the past academic year, an overview of which can be found in Table 2. Queries ranged from asking about coerced sex play, attempted sexual intercourse 
and completed sexual intercourse and respondents were directed to choose from a list of answers. Questions included "Has a anyone ever deliberately given you alcohol or drugs and engaged in sexual intercourse when you didn't want to?" or "Have you engaged in sex play (fondling, kissing or petting but not intercourse) when you didn't want to because someone used their position of authority (boss, teacher, counselor, supervisor) to make you?".

A univariate of analysis of respondents' reports of sexual coercion and assault showed that in the past school year over 30 percent of students answered that they had given in to sexual intercourse when they didn't want to because of continual pressure or arguments from the other person. Further analysis showed twenty-five percent of women reported they gave in to intercourse because of verbal coercion, whereas 6 percent of men and those identifying as non-binary answered affirmatively to this question. Only about four percent of all respondents answered that they had been pressured into sexual intercourse by someone using their authority to do so, and nearly 9 percent reported that they had been pressured into intercourse because of threats of physical force. While the percentage of students reporting they were pressured into sex because of authority, threats of physical force, or threats of violence were relatively low, those answering affirmative to these questions were predominantly female identifying. Almost 15 percent of respondents answered they had deliberately been given drugs or alcohol in a successful attempt to engage in sexual intercourse; of those, nearly 88 percent identified as women.

Based upon the answers to these queries, the survey asked a second series of questions based upon the respondents' victimization experiences. Students were asked to 
think about the most recent incident of unwanted sex play and/or unwanted intercourse. This differentiated the possibility of multiple experiences a respondent may have had with sexual assault. In this way student experiences were funneled into the queries regarding disclosure, place of incidence and relationship to the perpetrator; see Appendix C for the full text of the survey instrument.

One of these questions asked respondents whom they told about their sexual assault. Of those answering the question regarding disclosure $(\mathrm{N}=161), 56.6$ percent answered using a response category which indicated that they told some one about their assault. The remaining 43.4 percent related that they told no one of the incident. Response categories to this question were: no one, friend or family member, counselor, medical professional or clergy, police or other law enforcement, university disciplinary board, more than one of the above (please list), and other (with a space to type a response). Most students stated they told a friend or family member (38.5 percent). Only six (3.7 percent) people responded that they disclosed to a counselor, member of the clergy or doctor, and 2 people (1.2 percent) reported that they told police or law enforcement about their assault. For analytic purposes, this variable was operationalized dichotomously, recoding the response categories into 'told no one' and 'told someone'. Sixteen percent of the respondents to this question identified as male, but it is interesting to note that of these respondents over 60 percent stated they told no one about their assault. None of the male identified students made any kind of formal complaint, with nearly 20 percent of them stating they were unsure whether what happened was a crime. Sixty percent of those identifying as female did not make a formal complaint or report, 
and almost a quarter stated they were unsure if a crime occurred. Five percent of females stated they were afraid of repercussions from the perpetrator and 6 percent did not report because they were afraid of what their friends, family, or community would think.

\section{Independent Variables}

Based upon the literature, several independent variables were used to examine disclosure of sexual assault and coercion. These variables included respondent alcohol and drug use at the time of the incident, the other person's alcohol and drug use at the time of the assault, how well the respondent knew the perpetrator, where the incident took place, respondent's class standing, age, whether the perpetrator was a student, and whether the victim had ever attended sexual assault prevention training.

The connection between alcohol and sexual assault is a strong one, MessmanMoore et al. (2008) argue that alcohol and marijuana use are closely associated with increased rape vulnerability among college women. Table 3 gives an overview of victim and perpetrator alcohol and recreational drug use at the time of incidence. Nearly twothirds of respondents reported that they had not been drinking (63.1percent), 11.4 percent reported that they had been drinking but had not considered themselves intoxicated, whereas 25.6 percent responded that they had been drinking and were somewhat to very intoxicated at the time of the incident. A univariate analysis of respondent drug use showed that respondents overwhelmingly were not using recreational drugs $(86.3$ percent) at the time of their assault. Similar to Messman-Moore's et al. (2008) findings, Sanday (2007) and Burnett et al. (2009) found that college men who sexually assault women generally do so during or after gatherings where both parties have been drinking. 
Respondents reported that over a third of the other people involved (34.8 percent) had been drinking at the time of the assault. Further, eight percent were reported to have been somewhat to very intoxicated at the time. Nearly seventy percent of respondents reported that the other person was not using drugs at the time of the incident.

Participants were asked where the assault took place, a third were reported to have taken place in the perpetrator's dorm room, home or apartment (33.1percent) and over two fifths (41 percent) were reported to have taken place in the victim's domicile. Only about 15 percent of assaults took place in public spaces such as at parties, parking lots, or in lodgings such as motels or hotels.

Women will often not formally report if the sexual assault has been perpetrated by someone they know; often the closer the perpetrator is to the victim, the less likely she is to report the crime, and often will not even disclose what happened to a friend (Dunn et al. 1999; Sable et al. 2006; Banyard et al. 2005). Consistent with the literature, 44 percent reported that the perpetrator was a significant other or date, while 24 percent responded that the other person was an acquaintance. Cross tabulations by gender revealed that almost half of female respondents indicated they knew the other person very well. Written responses to the 'other' category included "friend", “college friend", and "coworker".

Nearly half, 45.6 percent, indicated that the other person involved in the incident was a student, and three quarters identified the other person as identifying as male. Only about a third of students stated they had ever attended a sexual violence prevention class, seminar or training, with approximately equal numbers of men and women stating they attended such a class. 
Respondents were asked to provide their gender identity in hope of examining the sexual assault experiences of those whom identify as non-binary; the bulk of the literature focuses on women, as they experience the greatest number of sexual assaults (Armstrong et al. 2006; Banyard et al. 2007; Cleere and Lynn 2013; Kolivas and Gross 2007; Koss 1998, 2011; Krebs et al. 2007; Lindquist et al. 2009; Sanday 2007; Sinozich et al. 2014; Wolitzky-Taylor et al. 2011). However, literature suggests that men also experience unwanted, coerced, or forced sex, and those who identify as lesbian, gay, transgender, or non-binary experience this at even higher rates averaging 4 to 5 percent higher that their heterosexual counterparts (Banyard et al. 2007; Beaulieu et al. 2017; Coulter et al. 2017; Ollen et al. 2017). In the survey instrument, respondents were asked to choose between a gender identity of male, female, transgender, and other with the option of writing in their preferred gender identity. Since those that identified outside of female and male gender categories was low, this variable was simplified to marry the transgender and other categories into one, which was then labeled 'non-binary'; leaving a three-category categorical variable with the response categories of: male, female and non-binary. This variable was later transformed into three dummy variables in which 1 was coded as identifying as that particular gender, and 0 was all others.

Students were asked to answer questions regarding the most recent incidence of sexual coercion, and/or sexual assault they had experienced. For logistic regression models to be constructed, variables needed to be dichotomized. The dependent variable, 'Whom did you tell', originally had several categories which allowed respondents to specify whom they told about their experience of sexual assault; these included: no one, 
friend or family member, counselor, medical professional, or clergy, police or law enforcement, university disciplinary board, more than one of the above (please list), and other. These response categories were subsequently dichotomized into "Told Someone" and "Told No One". Similarly, the independent variables for the model were transformed. Questions regarding whether the respondent was drinking or using recreational drugs at the time of the incident, whether the other person involved was drinking or using recreational drugs, and whether the respondent had ever attended sexual assault prevention training were simplified for analyses with responses such as 'not sure' and 'decline to answer' treated as missing. The student's relationship to the perpetrator was originally a multiple category question; for analysis the responses were grouped into four categories: Date/significant other, acquaintance, stranger, and 'other', like the other multiple category questions, 'decline to answer' and 'not sure' responses were treated as missing. 


\section{CHAPTER 4}

\section{FINDINGS}

Participants

Table 1 gives an overview of participant demographics. Of the 393 students who responded to the survey, 17.2 percent identified themselves as freshmen, 15.9 percent were sophomores, 30.4 percent identified at the junior level and nearly 30 percent indicated they were seniors. The average respondent age was $24.5(\mathrm{SD}=9.3)$. Approximately forty percent indicated that their age was between eighteen and twenty; 29.2 percent stated their age was between twenty-one and twenty-three; 9.8 percent fell between the ages of twenty-four and twenty-six; and 30.6 percent of students were twenty-seven or older. Age and class standing were important to examine as previous research has shown a higher number of sexual assault victimization among younger women and incoming freshmen (Banyard et al. 2005; Carey et al. 2015; Guerette and Caron 2008; Peterson and Muehlenhard 2004; Sinozich and Langton 2014).

Unsurprisingly, respondents were overwhelmingly female, with over seventy percent identifying as such. Those identifying as male made up about a quarter of respondents, and only about four percent identified as being non-binary. This is concurrent with the literature which has found that women generally make up the majority of those experiencing and disclosing about unwanted sexual experiences and sexual assault (Banyard et al. 2007; Brake 2017; Morgan and Kena 2017; Sinozich et al. 2014; Streng and Kamimura 2017). However, in the last few decades, research has also broadened the spectrum of victimization, making sure to include those who identify as male and those identifying as non-binary (van der Bruggen and Grubb 2014; Coulter et 
al. 2017; Freyd 2014). Similarly, a majority of the students, 69.4 percent, indicated that they identified as heterosexual, while 5.4 percent identified as gay or lesbian, 13.2 percent self-identified as bi-sexual, and 11.8 percent identified as Other. Written responses to the Other category included "asexual" and "pansexual". The literature suggests that those students who identify as non-heterosexual are at higher risk of sexual victimization, so incorporating sexual identity into the research instrument was important (Beaulieu et al. 2017; Ollen et al. 2017; Peterson and Muehlenhard 2004; Süssenbach et al. 2017).

Nearly 75 percent of respondents indicated themselves to be white or Caucasian; approximately 10 percent stated they considered themselves Hispanic/Latino/a, almost 6 percent described themselves as Native American, 3.8 percent indicated they were Asian, just over 2 percent stated they were Black/African American, 2 percent indicated they were Pacific Islander/Alaskan Natives, and 1.5 percent indicated they considered themselves to be Other. Written responses to the Other category included Middle Eastern and Punjabi.

Respondents were given a series of questions regarding their alcohol drinking habits for the 2014-2015 academic year. Nearly 17 percent stated they did not drink or had not drunk since the beginning of the school year, whereas 26.8 percent stated they drink less that once a month but had drank at least once since the beginning of the academic year. Almost a third of students responded they drank between one to three times a month, and 17.3 percent stated they drank between one to two times per week. Almost 10 percent responded that they drank more than twice a week. When asked how many times they drank to the point of drunkenness since the start of the academic year, 
nearly fifty percent responded that they had not become drunk at all in the average month, though over a quarter stated they had become drunk at least one time per month. A nearly equal number of students responded that they were drunk between two and five times a month, and almost six percent stated they drank to the point of drunkenness six to nine times in the average month, only 3 percent stated they became drunk ten or more times a month since the beginning of the academic year.

Armstrong et al. (2006) posits that where students imbibe can be an important detail when exploring college sexual assault, because many sexual assaults that occur within the college context are fueled by drinking and occur during or after college parties. Asking where they primarily drank when they imbibed, participants were given a choice of venue and the survey structure allowed for more than one response; the data indicated that students primarily drank in their own homes, the homes of others, or in a pub or restaurant. Fewer than 20 percent indicated they drank at parties. Those students in the 18 to 20 age range stated they primarily drank in their own homes, or in the home of someone else; this is unsurprising given that these students are unable to drink legally in public establishments. This age group also indicated they drink at parties more than other age groups. Those between the ages of 21 and 23 indicated that they too, primarily drink in their own homes, but stated they also drank at pubs and restaurants in greater numbers than any other age group. Overall, almost half of students, regardless of age, stated they primarily drank in their own homes, and nearly forty percent stated they drank in the home of someone else. Only about a quarter of respondents stated they normally drank in a pub or restaurant, and less than a fifth indicated they drank at parties. 
When asked if they had ever engaged in consensual sexual intercourse, 84.2 percent of participants indicated they had. Asking whether a student had consensual but unwanted sexual intercourse, about 42 percent stated that they had engaged in unwanted but consensual sex. This is important because the literature suggests that many acts of unwanted but consensual sex meet the legal definition for assault, but are culturally looked as 'bad dates' or 'bad hook-ups' (Cleere and Lynn 2013; Peterson and Muehlenhard 2007).

Table 4 gives a comparative overview of the university demographics, survey population, and analytic population. Twice as many freshmen, by percentage, were represented in the analytic sample as were attending Southern Oregon University in May of 2015. Likewise, 10 percent more juniors were represented in the analytic sample as the overall university population. By percentage, women were overrepresented in the analytic population by a little over 20 percent. Conversely, men were underrepresented in the analytic sample by 23.3 percent. Those identifying as non-binary were overrepresented in the analytic sample as well, with 4.3 percent versus the 2.4 percent represented in the larger university population.

\section{Bivariate Analyses}

Table 2 describes crosstabulations between the dependent and independent variables. Consistent with the literature, disclosure of sexual assault was split nearly evenly between disclosure and non-disclosure within the 18-20 age group, 54.9 and 45.1 percent respectively. This group was also the largest represented in the data, making up 51.3 percent of the 160 respondents to the question. The data shows that as age goes up, a 
greater number of students appear to have disclosed to someone about their assault (see Table 5). However, within this age group, and the undergraduate student population as a whole, the relationship between disclosure and age was a non-significant one $\left(\chi^{2}=1.639\right.$; $\mathrm{p}=.650$ ). Likewise, class standing yielded non-significant findings when examining disclosure $\left(\chi^{2}=4.666 ; p=.323\right)$. Here the largest number of students disclosing victimization also reported having junior or senior class standing, 53.3 and 68.1 percent within their groups, respectively.

Of those reporting the incident took place in their own home, apartment or dorm room, 55.2 percent told no one about the assault. Of those reporting the incident took place in the other person's home, apartment, or dorm room, 63.6 percent reported disclosing to someone about the assault. The relationship between the place the incident occurred, and disclosure was a non-significant one $\left(\chi^{2}=8.301 ; \mathrm{p}=.081\right)$.

Those students reporting that they had not been drinking at the time of the assault had a higher instance of disclosure, with 51.5 percent of these students reporting they disclosed to someone. Interestingly, of those relaying they had been drinking at the time, 65 percent stated they had disclosed the assault to someone else. However, the relationship between the victim's drinking habits and disclosure was a non-significant one $\left(\chi^{2}=.094 ; \mathrm{p}=2.798\right)$. Also, statistically non-significant was the relationship between disclosure and the perpetrator drinking at the time of incidence. Nonetheless, 53.9 percent of students that reported the other person was drinking at the time of the assault disclosed the incident to someone else. The data yielded similar findings when asking about recreational drug use and disclosure. Overwhelmingly, students reported not being under 
the influence of recreational drugs at the time of the assault, with over half, 55.5 percent, reporting that they disclosed the victimization; however, the relationship was not statistically significant $\left(\chi^{2}=.233 ; \mathrm{p}=.629\right)$. Whether the other person was using recreational drugs at the time of the incident was also non-significant when related to disclosure $\left(\chi^{2}=.241 ; \mathrm{p}=.624\right)$. More than half of participants reported that the other person was not using recreational drugs at the time of incidence, with 56.6 percent reporting that they told some one about the occurrence. However, crosstabulation analysis showed a significant relationship between disclosure and whether a respondent reported deliberately being given drugs or alcohol to facilitate $\operatorname{sex}\left(\chi^{2}=13.263 ; \mathrm{p}=.000\right)$.

Gender appeared to be a statistically significant relationship when considering disclosure of sexual assault $\left(\chi^{2}=4.138 ; \mathrm{p}=.042\right)$. Over half of those identifying as female reported disclosing their victimization to someone, while nearly a third said they told no one. Over ten percent of the total respondents identified as male and 61.5 percent reported they told no one of their assault; this is concurrent with the literature regarding gender and disclosure practices.

The relationship to the perpetrator was also a statistically significant relationship to disclosure $\left(\chi^{2}=10.349 ; \mathrm{p}=.006\right)$. Twenty-five percent of students reported that the person was their significant other or date, and of those 57.1 percent told no one of the incident. Concurrent with the literature, of those reporting that the incident occurred with an acquaintance, 73.7 percent indicated they disclosed the assault to someone else. It can be concluded in this case, that the close relationship between perpetrator and victim is an important and statistically significant one when examining inter-partner sexual violence. 
This is in accordance with the literature, which asserts that many sexual assaults are perpetrated by someone close to the victim and often the victim is reticent to disclose the assault (Bletzer and Koss 2004; Dunn et al. 1999; Kahn et al. 2003; Rickert et al. 2005). Statistically significant to disclosure was the relationship the victim had with the perpetrator; more specifically, being sexually assaulted by their significant other or date had a significant relationship to disclosure; this was found to be strongly significant when rendering the categorical variable as a dummy variable for multivariate analyses. In this case, crosstabulation of the dichotomized variable isolating significant other or date and the dependent variable found the relationship was highly significant $\left(\chi^{2}=9.970 ; \mathrm{p}=.002\right)$.

\section{Logistic Regression Model}

Based upon the literature, and bivariate analyses of the data regarding disclosure, variables which would best explain the determinants of disclosure among the student population were chosen. The first model examines how gender identification impacts victim disclosure. Each successive model adds additional predictor variables considered pertinent based upon the literature; these variables include gender identification, victim age, place of incidence, relationship to the perpetrator, class standing, whether the victim had ever been given drugs or alcohol deliberately in the past to facilitate sex play or intercourse, and whether the victim had attended a sexual assault prevention class.

The dependent variable was dichotomized and transformed into a dummy variable for analysis. Dichotomized as an indicator for disclosure, the dependent variable was operationalized with those respondents having told someone of their assault coded as 1 and those who did not disclose coded as 0 . Since the research was interested in the 
disclosure practices of men, as well as women and those who identify as non-binary, dummy variables were constructed for all gender identities; with 0 labeling all others, and 1 labeling gender identity as male, female, and nonbinary respectively. The model examined first the effect of being male identified upon disclosure, with women and nonbinary as reference groups. Although the number of those identifying as non-binary and reporting victimization was small, the model also explored how this gender identification impacts disclosure, again with female identified respondents as a reference category. Place of incidence was examined, and given the non-ordinal nature of the variable, the categories were dichotomized with 1 as being the place the assault occurred, and 0 being all other response categories; those included in analysis were: having been assaulted on one's own home, apartment or dorm and those responding that they had been assaulted in the perpetrator's home, apartment, or dorm. Those reporting that they had been deliberately given alcohol or drugs in order to facilitate sex play and sexual assault were examined; here the variables were simplified with the response category of 'decline to answer' treated as missing. Finally, attendance of a sexual assault prevention class was examined; here the responses were dichotomized and coded 1 for yes, having attended a sexual assault prevention class, and 0 for no, never having attended such a class. As with previous variables, the response category of 'not sure' was coded as missing.

It is important to note that regressions were run with variables describing whether a victim had been drinking or using recreational drugs at the time of the assault. Additionally, perpetrator alcohol and recreational drug use was examined, though all four variables were non-significant in bivariate analyses. These four variables were positively related but non-significant. In another iteration of the regression model, the interactions 
of the four variables were examined within the regression analyses, again they were positively related, but non-significant. It was then decided to exclude these variables from the final regression model, as it appeared that they did not influence the probability of disclosure in a statistically significant way.

Table 6 presents both the unstandardized logistic coefficients and the odds ratios (in parenthesis) for all ten variables in the seven models. A significant odds ratio with a value below 1 indicates that the odds of disclosure are reduced; conversely, an odds ratio with a value over 1 indicates an increase in the odds of disclosure. Subtracting 1 from the odds ratios in the table and multiplying by 100 gives the odds of disclosure in a percentage form. As a result, the odds ratios in the table represent the likelihood of a respondent disclosing their assault to someone.

The first model examines the predictive power of gender on disclosure practices. In this case, identifying as male was negatively related and significant, and remained so through the first three models of the regression analyses. That is, male identified undergraduates are 58.3 percent less likely to disclose a sexual assault. The relationship between being male identified and disclosure remained negative throughout the models but was rendered non-significant when controlling for place of incidence, relationship to the perpetrator, class standing, and attendance of sexual assault prevention classes.

Model two introduced students who identified as non-binary. Within models one and two, female identified students were used as a reference category. Identifying as nonbinary appeared to have a negative, though non-statistically significant effect on disclosure when controlling for age. 
Model three examined the effect of age upon disclosure of sexual assault. The relationship was positive, though non-significant when introduced and when controlling for place of incidence and relationship to the perpetrator. However, the relationship to disclosure became negative when controlling for class standing, having deliberately been given drugs or alcohol to facilitate sex play or intercourse, and attending sexual assault prevention class. The coefficient for age groups remained non-significant throughout.

The predictive power of the place of incidence and relationship with the perpetrator was examined in model four. The coefficient regarding having been assaulted in one's own home, apartment, or dorm room was negatively related to disclosure throughout all models, though non-significant. Similarly, the relationship between reporting the assault happened in the other person's home, apartment, or dorm room was positively related to disclosure, but also non-significant throughout. The relationship between the victim and the perpetrator, that is perpetrators identified as a significant other or date, was shown to be a strongly statistically significant variable. The coefficient was negatively related throughout; in models four, five, and seven the relationship was a statistically significant predictor of sexual assault disclosure. When controlling for attendance to a sexual assault prevention class, victims were 60.8 percent less likely to disclose their assault. However, when controlling for class, and having deliberately been given drugs or alcohol to facilitate sex play or intercourse the variable was rendered nonsignificant.

Model five examined the predictive power of class standing and found the coefficient was positively related to disclosure and was statistically significant when controlling for having deliberately been given drugs or alcohol to facilitate sex play or 
intercourse and attendance of a sexual assault prevention class. The relationship remained positively related throughout all models, and the likelihood of disclosure appears to increase with each step up in class standing.

Incapacitated sex play via drugs or alcohol was non-significant in multivariate analyses, though positively related to disclosure. Conversely, a history of having been deliberately been given drugs or alcohol to facilitate intercourse was highly statistically significant in model six and positively related; students were 271.5 percent more likely to disclose if this had happened to them. Controlling for attendance of sexual assault prevention classes rendered the coefficient slightly less significant but still positively related. Odds ratios increased through subsequent models, meaning that those who were given drugs or alcohol purposely to enable non-consensual intercourse were more likely to disclose having been assaulted.

The final model examined the relationship between disclosure and attendance of a sexual assault prevention class. The coefficient regarding attendance of such a class was positively related, but non-statistically significant.

The models within this logistic regression had decreasing $-2 \log$ likelihood values, indicating subsequent models within the regression were better able to explain determinants of disclosure. In modelling determinants of disclosure, the number of cases in model one was 161, however, once subsequent controls were added into the model the final number of cases was 136. In order to better examine these 136 cases throughout all iterations of the regression models, a second analysis was performed using a nested model. More specifically, standard error associated with regression coefficients may be biased, which could lead to incorrect deductions about the statistical significance of the 
observed relationships. By nesting the data, this can be corrected and allows group characteristics to be included in the models of the individual outcomes. Hence the determinants of disclosure were analyzed within these parameters and the number of cases examined in each model was 136.

Table 7 presents both the unstandardized logistic coefficients and the odds ratios (in parenthesis) for all nine variables in the seven models, and the models exactly mirrored those of the first analyses. The predictive power of being male identified remained negatively related to disclosure throughout, and like the first regression, was significant in models one through three. However, the within this analysis, a male, relative to all other gender identifications, was 61.7 percent less likely to disclose his victimization; within the non-nested regression male identified individuals were 58.3 percent less likely to disclose. Identifying as non-binary continued to be negatively related to disclosure of sexual assault in all models and remained non-significant.

Model three's introduction of age groups was positively related until controlling for class standing, afterward staying negatively related and non-significant throughout. This variable's finding closely mirrored that of the first set of analyses.

Like the previous analysis, the coefficient regarding having been assaulted in one's own home, apartment, or dorm room was negatively related throughout all models, but remained non-significant. Having been assaulted in the perpetrator's home, apartment, or dorm room was likewise positively related and non-significant throughout all models.

The coefficient regarding relationship to the perpetrator was strongly significant in models four and five, and negatively related throughout. Unlike the previous 
regression, this variable remained statistically significant when controlling for having deliberately been given drugs or alcohol to facilitate sex play or intercourse (model six). The likelihood of non-disclosure for someone reporting that the perpetrator was a significant other or date was 65.2 percent; interestingly, this likelihood of non-disclosure decreased, with those victims 60.8 percent less likely to disclose when controlling for class standing, drug or alcohol facilitated sex play and intercourse, and attendance of a sexual assault prevention class.

Within this nested regression, having deliberately been given drugs or alcohol to facilitate sex play was positively related to disclosure, but non-significant. The coefficient regarding having been intentionally drugged or given alcohol to facilitate intercourse was positively related and statistically significant with respondents being 302.4 percent more likely to disclose in this analysis. This likelihood of disclosure increased by 31 percent over the non-nested model. Likelihood decreased slightly when controlling for attendance to a sexual assault prevention class but remained significant. Having attended a sexual assault prevention class remained statistically non-significant and positively related.

This regression began with a markedly lower $-2 \log$ likelihood coefficient than the non-nested regression and continued to decrease as models were added to the analyses. This suggests that the nested regression was a better statistical fit in explaining predictors of disclosure of sexual assault. 


\section{CHAPTER 5}

\section{DISCUSSION}

The current study sought to examine the determinants surrounding disclosure of sexual assault on a college campus which has historically been progressive in its policies regarding sexual assault awareness, training and reporting. This institution has cultivated a climate of acceptance and diversity, making it an interesting choice to examine sexual assault disclosure. The results of this research suggest that even at a school with no popular athletics or Greek system in place, students are still reluctant in many cases to disclose their sexual assaults.

It was hypothesized that gender would influence disclosure; and those individuals identifying as male would be less likely to disclose an incident of sexual assault. Consistent with this hypothesis, the study showed that male students were far less likely than their female counterparts to disclose. This is concurrent with the literature regarding barriers to disclosure which states that gender roles and the stigma and cultural values attached to male sexual assault make it hard for male victims to disclose or seek help following victimization (Allen, Ridgeway, and Swan 2015; Banyard et al. 2005; Flack et al. 2007; Sable et al. 2006). Moreover, current studies have shown that higher male adherence to rape myths can also impact disclosure, as men are more likely to believe that they cannot be victimized, or that their masculinity will come into question should they disclose being a victim (Hayes et al. 2016). Those individuals identifying as nonbinary were less likely to disclose their sexual assaults, based upon the regressions in this study, however, the results were non-significant in multivariate analyses. Still, this 
finding concurs with the literature, which posits that non-binary individuals are less likely to disclose or report instances of victimization (Potter, Fountain, and Stapleton 2012).

Consistent with the hypotheses, the relationship with the perpetrator was important to disclosure. In multivariate analyses having been assaulted by a significant other was found to be significantly and negatively related, which indicates that a close relationship to the attacker has a negative impact on disclosure. These findings align with the literature which posits that sexual assault between intimate partners is often unreported and undisclosed, and could be due in large part to victims' reluctance to label their experience with someone close to them as sexual assault, fear of retaliation, and fear of not being believed (Ahrens et al. 2007; Littleton and Axsom 2003; Moors and Webber 2012; Potter et al. 2012; Sable et al. 2006; Zinzow and Thompson 2011). Findings like these tie into the assertion that intimate partner sexual violence is often not labelled as sexual assault by the victims, but rather as a 'miscommunication' or considered a 'private matter' (Benson et al. 1992; Bletzer and Koss 2004; Giraldi and Monk-Turner 2017; Littleton and Axsom 2003; Nabors and Jasinski 2009; Orchowski and Gidycz 2012; Sable et al. 2006).

Hypothesizing that age would factor into disclosure practices, findings indicated that age is an influence in disclosure, although regression analyses showed that age was a non-significant predictor. This is interesting given that the literature indicates that younger students are more at risk for sexual assault and less likely to disclose (Armstrong et al. 2006; Sinozich et al. 2014). Likewise, the multivariate analyses suggest that class standing was positive determinant of disclosure; that is, the higher in class 
standing, the more likely a student is to disclose. This is consistent with the literature which asserts that those in their freshman and sophomore years are more likely to be victims of sexual assault, and less likely to recognize the incident as a crime or disclose their victimization (Krebs et al. 2007; Sinozich et al. 2014). Armstrong et al. (2006) posit that alcohol consumption and partying early within the college experience is a cultural phenomenon in which many college students participate. Linking party behavior with alcohol expectancies and the cultural values surrounding over-imbibing and blame for sexual assault, it is unsurprising that younger students are reticent to disclose (Coulter et al. 2017; Fisher et al. 2000; Krebs et al. 2007; Messman-Moore et al. 2008).

Having been the victim of drug or alcohol facilitated sexual assault was a significant predictor of disclosure, which was interesting given much of the literature surrounding drug or alcohol facilitated non-consensual intercourse which notes that victims of this type are less likely to report their experiences (Franklin 2010; Kilpatrick et al. 2007). This research found that this type of victimization was shown to increase the likelihood of disclosure.

The results indicate that relationship to the perpetrator and having a history of drug or alcohol facilitated sexual assault are some of the most reliable predictors of disclosure of sexual assault among students on this campus. This is unsurprising given the literature surrounding interpersonal violence and disclosure of sexual assault and these findings align with the current research (Coulter et al. 2017; Donde et al. 2018; Kilpatrick et al. 2007; Krebs et al. 2007; Messman-Moore et al. 2008; Muehlenhard et al. 2017). 
Interestingly, even though having attended a sexual assault prevention class was non-significant in both bivariate and multivariate analyses, it is important to note that the variable influenced disclosure of sexual assault in both logistic regressions. Within the models, attendance of a sexual assault prevention class increased the likelihood of disclosure.

\section{Conclusion}

The literature suggests that undergraduate students in their first years at university are more vulnerable to sexual assault and less likely to disclose or report those assaults (Ahrens et al. 2007; Armstrong et al. 2006; Messman-Moore et al. 2008; Muehlenhard et al. 2017). When considering this through the lens of Critical Feminist Theory, power structures inherent within the hierarchy of student life at universities in general would explain the lack of disclosure on younger students' part. That is, younger students who are new to the university system and the partying scene would seek to emulate their older peers and look to them for guidance in behavior; hence the informal power structures already in place which foster silencing and shame regarding sexual assault in turn silence younger and less experienced victims (Iverson 2016). Further, the power inherent in formal structures, that is, university policy regarding disclosure and reporting of sexual assault, put in place to help victims often have the opposite effect by making victims question the validity of their experiences and fear secondary victimization within the reporting and adjudication process (Brown and Mangan 2018; Howle and Cordiner 2013; Iverson 2016). 
Dominant discourses within college culture often frame sexual assault as a communication error or misunderstanding between partners exacerbated by alcohol use; within this paradigm it is easy to imagine victims' reticence regarding disclosure and reporting (Haaken 2017). Moreover, male victims of sexual assault within these discourses are often not taken seriously or have their sexuality questioned should they come forward and disclose their experiences (Sable et al. 2006).

Previous research suggests that sexual assault prevention classes can help bridge the cultural gap between instances of sexual assault and the victims labelling it as such; moreover, these types of classes, administered early within the college experience have the potential to increase disclosure and reporting rates of sexual misconduct (Howle and Cordiner 2013; Krebs et al. 2007; Schwartz and Leggett 1999; The White House Task Force to Protect Students From Sexual Assault 2014). Indeed, the 2013 amendment to the Clery Act mandates that universities must train both staff and students about sexual assault awareness (Cox 2018). Given the effect that attending a sexual assault prevention class had on disclosure practices, these mandatory sexual assault prevention classes in the first and possible second years could have a positive effect on future disclosure. Further, the current research suggests that the role of gender plays a large part in how the messages of sexual assault prevention are absorbed into the student consciousness, therefore single-gender classes and specialized programming could help deepen the message regarding prevention, disclosure, and reporting (Banyard et al. 2007; Streng and Kamimura 2017). By teaching bystander awareness as well as sexual assault prevention, these educational measures have the potential to change college cultural understandings 
of sexual assault (Banyard 2014; Cox 2018; Potter et al. 2012). Changing campus culture surrounding what constitutes 'real' sexual assault could help bridge the gap between the letter of law and the culturally influenced ideas of what sexual victimization looks like.

Employing the proven research instruments of previous researchers, this study examined determinants of disclosure of sexual assault among a specific college population. That said, although the current study offers support for previous research regarding disclosure of sexual assault, there are limitations to the study. The limitation of use of this survey on one campus, with a relatively small analytic population limits generalizability. Duplicating the study on other campuses with similar demographics would allow for a greater level of generalizability and better overall understanding of the circumstances and determinants of disclosure among college students. It is also important to note, that due to the sensitive nature of the questions, students may not have completed the survey, deeming it triggering, resulting in the smaller analytic sample size.

Southern Oregon University is predominantly Caucasian and initial analyses showed that race and ethnicity did not factor prominently into disclosure practices and were therefore excluded from subsequent analyses. Further research should include race and ethnic considerations as influential mechanisms to disclosure of sexual assault on college campuses, as previous research has shown that cultural background and values can influence disclosure and reporting practices (Bletzer and Koss 2004; Koo et al. 2015). Moreover, the respondents of this survey were by and large male and female identifying; further research regarding the experiences of those identifying as non-binary and their disclosure practices would be beneficial to understanding how this group 
experiences disclosure after a sexual assault, given the small number of non-binary individuals in the analytic sample.

Research regarding disclosure of student sexual assault has a gap within the current literature. A majority of literature regarding student disclosure has centered upon women's experiences, presence of a Greek system, and student adherence to traditional gender roles. Other research has examined barriers to disclosure and reporting, and student reaction to having a sexual assault disclosed to them. This study provides another facet to disclosure by examining determinants of disclosure among students of all gender identifications on a campus with no Greek system or popular athletics. Adherence to traditional gender roles was not explored, but rather student experience and circumstance surrounding their victimization which led to disclosure or non-disclosure of their assault. The results of the study indicate that interpersonal violence among dating partners, a history of incapacitated rape, and class standing may be very important touch stones for disclosure of sexual assault. These findings add to the literature about disclosure and sexual assault on college campuses, by highlighting disclosure among a student population which lacks a definitive party scene and Greek culture. Moreover, by not centering strictly on the experiences of women, the disclosure practices of men and nonbinary individuals who experience assault can be better understood.

The findings regarding attendance of sexual assault prevention classes, and the impact this had upon other determinants of disclosure opens the way for more meaningful discourse regarding mandatory sexual assault prevention classes and policy regarding such classes in student orientations and throughout the student experience. Previous 
research has shown that prevention classes, given multiple times and utilizing various media platforms are effective measures in curbing sexual assault and increasing reporting rates, it stands to reason that more aggressive prevention education measures would also increase the likelihood of disclosure (Banyard 2014). Given the literature regarding experiences commensurate with the legal definitions of sexual assault that are often not acknowledged by the victims as such, prevention education policies also have the potential to help victims realize what happened to them was a sexual assault, allowing them the language and resources to disclose, should they wish to.

More research regarding the links between disclosure and the circumstances surrounding disclosure on college campuses which do not have a Greek system or popular athletics could help better understand the dynamics surrounding disclosure and assist current programming to increase reporting rates. Further, college educational programing regarding sexual assault, interpersonal violence, and use of campus resources may help in increasing disclosure and reporting. 
Table 1: Overall Demographic Frequencies

Class Standing: $(\mathrm{N}=296)$

$$
\text { Variable }
$$

Freshman
Sophomore
Junior
Senior

Age Range: $(\mathrm{N}=392)$

Post-baccalaureate

$$
\text { 18-20 }
$$

21-23

24-26

27 and above

Gender Identity: $(\mathrm{N}=327)$

Sexual Identity (N=204)

Female

Male

Non-binary

Heterosexual

Gay or Lesbian

Bisexual

Other
Frequency

Asian

Black/African American

Hispanic/Latino/a

Native American

Pacific Islander/Alaskan Native

White/Caucasian

Other

How often do you drink alcohol? ( $\mathrm{N}=295)$

Never/not this school year

Less that once a month/once this school year

1-3 times a month

1-2 times a week

More than twice a week

How many times have you become drunk in the average month?

$(\mathrm{N}=294)$

\section{Never \\ Once \\ 2-5 times \\ 6-9 times}

10 or more times

Where do you normally drink? $(\mathrm{N}=392) *$

\section{Own home}

Party

Pub, bar, or restaurant

Someone else's home

Other
51

47

90

94

14

131

95

32

67

234

78

15

142

11

27

24

Percent

17.2

15.9

30.4

31.8

4.7

40.3

29.2

9.8

20.6

71.6

23.9

4.6

69.6

5.4

13.2

11.8

$\begin{array}{ll}15 & 3.8\end{array}$

$\begin{array}{ll}9 & 2.2 \\ 38 & \end{array}$

$\begin{array}{ll}38 & 9.7\end{array}$

$\begin{array}{ll}23 & 5.9\end{array}$

$8 \quad 2.0$

$290 \quad 74.0$

$6 \quad 1.5$

$\begin{array}{ll}50 & 16.9\end{array}$

$\begin{array}{ll}79 & 26.8\end{array}$

$\begin{array}{ll}88 & 29.8\end{array}$

$51 \quad 17.3$

27
27.2

\section{8 \\ 1.5

.2

7

0

- -1

-8
17.3

$\begin{array}{cc}113 & 38.4 \\ 79 & 26.9 \\ 76 & 25.9 \\ 17 & 5.8 \\ 9 & 3.1 \\ & \\ 195 & 49.7 \\ 71 & 18.1 \\ 105 & 26.7 \\ 149 & 38.0 \\ 16 & 4.1\end{array}$

*Respondents were able to choose more than one repose categories to these questions resulting in totals of more than 100 percent. 
Table 2: Situational Frequencies

\section{Variable}

Have you ever had intercourse with another person when you both wanted to? $(\mathrm{N}=285)$

$$
\text { Yes }
$$$$
\text { No }
$$

Have you ever had someone misinterpret the level of sexual intimacy you desired, that is, have you ever engaged in consensual unwanted sex?

$(\mathrm{N}=285)$

Yes
No

Have you ever engaged in sex play when you didn't want to because you were overwhelmed by the other person's continual arguments and pressure? $(\mathrm{N}=277)$

$$
\text { Yes }
$$$$
\text { No }
$$

Have you ever given in to sexual intercourse when you didn't want to because you were overwhelmed by the other person's continual arguments and pressure? $(\mathrm{N}=267)$

$$
\text { Yes }
$$

No

Have you ever engaged in sexual intercourse when you didn't want to because the other person used their position of authority to make you? $(\mathrm{N}=267)$

$$
\begin{aligned}
& \text { Yes } \\
& \text { No }
\end{aligned}
$$

Have you ever engaged in sexual intercourse when you didn't want to because the other person threatened physical force? $(\mathrm{N}=267)$

$$
\begin{aligned}
& \text { Yes } \\
& \text { No }
\end{aligned}
$$

Has anyone ever deliberately given you alcohol or drugs and attempted to engage in sexual intercourse when you didn't want to, but intercourse did not occur? $(\mathrm{N}=278)$

$$
\text { Yes }
$$$$
\text { No }
$$

Has anyone ever deliberately given you alcohol or drugs and engage in sexual intercourse with you when you didn't want to? $(\mathrm{N}=267)$

$$
\text { Yes }
$$

Have you ever taken a sexual assault prevention class, seminar, or training? $(\mathrm{N}=188)$

$\begin{array}{ccc}\text { Yes } & 67 & 32.8 \\ \text { No } & 122 & 59.8 \\ \text { Not Sure } & 15 & 7.4\end{array}$


Table 3: Disclosure, Alcohol and Drug Use Frequencies

$$
\text { Variable }
$$

Frequency

Percent

Whom did you tell? $(\mathrm{N}=161)$

No one

Friend or family member

Counselor, medical professional, or clergy

62

3.7

Police, or other law enforcement

1.2

More than one of the above (list)/Other

2

12

Were you drinking at the time? $(\mathrm{N}=176)$

$$
\text { No }
$$

63.1

Yes, but not intoxicated

Yes, somewhat intoxicated

11.4

Yes, very intoxicated

9.7

17

15.9

Was the other person drinking at the time? $(\mathrm{N}=175)$

$$
\text { No }
$$

Yes, but not intoxicated

56.6

Yes, somewhat intoxicated

Yes, very intoxicated

Unknown

Were you using recreational drugs at the time? $(\mathrm{N}=175)$

$$
\text { No }
$$

8.8

Yes, but not high

Yes, somewhat high

Yes, very high

Was the other person using recreational drugs at the time? $(\mathrm{N}=175)$

No

What was the nature of your relationship with the other person?

Significant other/date
Acquaintance
Stranger
Authority Figure/Family Member
Other
person involved a student? $(\mathrm{N}=168)$

Was the other person involved a student? $(\mathrm{N}=168)$

Yes

No

Where did it occur? $(\mathrm{N}=157)$

Own Home, apartment, dorm room 
Table 4: Demographics Comparison by Percentage

$$
\text { University population }
$$

Survey Respondents

$$
(\mathrm{N}=4,376)
$$

$(\mathrm{N}=393)$

Analytic Sample

Class Standing

Freshman

11.1

17.2

15.9

Junior

13.4

19.2

31.8

30.4

31.8

$(\mathrm{N}=161)$

Senior

58.2

Male

39.4

2.4

71.6

23.9

Non-Binary

4.6

22.5

17.5

28.1

29.4

79.5

16.1

4.3 
Table 5: Crosstabulation of respondents' disclosures by percentage $(\mathrm{N}=160)$

\section{Whom did you tell? \\ No one Someone}

Age Category: $\left(\chi^{2}=1.639 ; \mathrm{p}=.650\right)$

18-20

$45.1 \quad 54.9$

21-23

$41.7 \quad 58.3$

24-26

$25.0 \quad 75.0$

27 and above

$50.0 \quad 50.0$

Class Standing: $\left(\chi^{2}=4.666 ; \mathrm{p}=.323\right)$

Freshman

$47.2 \quad 52.8$
53.6

Sophomore

$53.6 \quad 46.4$

Junior

$46.7 \quad 53.3$

Senior

$31.9 \quad 68.1$

Where did it occur? $\left(\chi^{2}=8.301 ; \mathrm{p}=.061\right)$

Own home/apartment/dorm room

$55.2 \quad 44.8$

The other person's home/apartment/dorm room

$36.4 \quad 63.6$

At a party/social gathering

$33.3 \quad 66.7$

Motor vehicle/Public Place

2.7

6.1

What was the nature of your relationship to the other person? $\left(\chi^{2}=10.349 ; \mathrm{p}=.006^{* *}\right)$

$\begin{array}{ccc}\text { Significant other/date } & 57.1 & 42.9 \\ \text { Acquaintance } & 35.9 & 73.7 \\ \text { Other } & 29.4 & 70.6\end{array}$

Has anyone ever deliberately given you alcohol/drugs to facilitate sex play? $\left(\chi^{2}=4.751 ; \mathrm{p}=.029 *\right)$

$\begin{array}{lll}\text { No } & 48.7 & 51.3 \\ \text { Yes } & 29.5 & 70.5\end{array}$

Has anyone ever deliberately given you alcohol/drugs to facilitate intercourse? $\left(\chi^{2}=13.263 ; \mathrm{p}=.000 * *\right)$

No

Yes

Were you drinking at the time? $\left(\chi^{2}=2.798 ; \mathrm{p}=.094\right)$

No

Yes

Was the other person drinking at the time? $\left(\chi^{2}=.461 ; p=.497\right)$

No

Yes

$52.1 \quad 47.9$

$18.4 \quad 81.6$

$48.5 \quad 51.5$

$35.0 \quad 65.0$

$46.1 \quad 53.9$

$40.3 \quad 59.7$

Were you using recreational drugs at the time? $\left(\chi^{2}=.233 ; p=.629\right)$

No

$44.5 \quad 55.5$

Yes

39.1

60.9

Was the other person using recreational drugs at the time? $\left(\chi^{2}=.241 ; \mathrm{p}=.624\right)$

No

$44.4 \quad 56.6$

Yes

39.3

60.7

Gender $\left(\chi^{2}=4.138 ; \mathrm{p}=.042 *\right)$
$61.5 \quad 38.5$

$39.8 \quad 60.2$ 
Have you ever attended a sexual violence prevention class, seminar, or training? $\left(\chi^{2}=1.386 ; p=.239\right)$

No

Yes
48.1

38.0

$* \mathrm{p}<.05, * * \mathrm{p}<.01$
51.9

62.0 


\begin{tabular}{|c|c|c|c|c|c|c|c|}
\hline Variable & $\begin{array}{l}\text { Model } \\
1\end{array}$ & $\begin{array}{l}\text { Model } \\
2\end{array}$ & $\begin{array}{l}\text { Model } \\
3\end{array}$ & $\begin{array}{l}\text { Model } \\
4\end{array}$ & $\begin{array}{l}\text { Model } \\
5\end{array}$ & $\begin{array}{l}\text { Model } \\
6\end{array}$ & $\begin{array}{l}\text { Model } \\
7\end{array}$ \\
\hline \multicolumn{8}{|l|}{ Gender } \\
\hline Male Identified $^{\text {a }}$ & $\begin{array}{r}-.875^{*} \\
(.417)\end{array}$ & $\begin{array}{r}-.882 * \\
(.414)\end{array}$ & $\begin{array}{r}-.903 * \\
(.405)\end{array}$ & $\begin{array}{l}-.625 \\
(.535)\end{array}$ & $\begin{array}{l}-.590 \\
(.554)\end{array}$ & $\begin{array}{l}-.557 \\
(.573)\end{array}$ & $\begin{array}{l}-.426 \\
(.653)\end{array}$ \\
\hline Non-binary ${ }^{b}$ & & $\begin{array}{l}-.124 \\
(.883)\end{array}$ & $\begin{array}{l}-.111 \\
(.895)\end{array}$ & $\begin{array}{l}-.189 \\
(.828)\end{array}$ & $\begin{array}{l}-.261 \\
(.770)\end{array}$ & $\begin{array}{l}-0.96 \\
(.908)\end{array}$ & $\begin{array}{l}-.068 \\
(.935)\end{array}$ \\
\hline Age & & & $\begin{array}{r}.061 \\
(1.062)\end{array}$ & $\begin{array}{r}.109 \\
(1.115)\end{array}$ & $\begin{array}{r}-.040 \\
(.961)\end{array}$ & $\begin{array}{r}-.238 \\
(.788)\end{array}$ & $\begin{array}{l}-.318 \\
(.728)\end{array}$ \\
\hline \multicolumn{8}{|l|}{ Place of Incidence } \\
\hline Own home/apartment/dorm ${ }^{c}$ & & & & $\begin{array}{l}-.406 \\
(.666)\end{array}$ & $\begin{array}{r}-.377 \\
(.686)\end{array}$ & $\begin{array}{l}-.144 \\
(.866)\end{array}$ & $\begin{array}{l}-.082 \\
(.922)\end{array}$ \\
\hline $\begin{array}{l}\text { Other person's home/ } \\
\text { apartment/dorm }\end{array}$ & & & & $\begin{array}{r}.135 \\
(.779)\end{array}$ & $\begin{array}{r}.065 \\
(1.067)\end{array}$ & $\begin{array}{l}-.004 \\
(.996)\end{array}$ & $\begin{array}{l}-.061 \\
(.941)\end{array}$ \\
\hline \multicolumn{8}{|l|}{ Relationship to perpetrator } \\
\hline Significant Other/Date ${ }^{\mathrm{d}}$ & & & & $\begin{array}{r}-.943 * * \\
(.389)\end{array}$ & $\begin{array}{l}-.928^{*} \\
(.395)\end{array}$ & $\begin{array}{l}-.767 \\
(.464)\end{array}$ & $\begin{aligned}-.937 * \\
(.392)\end{aligned}$ \\
\hline Class Standing & & & & & $\begin{array}{r}.277 \\
(1.319)\end{array}$ & $\begin{array}{r}.398^{*} \\
(1.489)\end{array}$ & $\begin{array}{r}.396^{*} \\
(1.486)\end{array}$ \\
\hline \multicolumn{8}{|l|}{ Alcohol and/or Drugs } \\
\hline $\begin{array}{l}\text { Deliberately given } \\
\text { alcohol/drugs to facilitate } \\
\text { sex play }\end{array}$ & & & & & & $\begin{array}{c}.232 \\
(1.262)\end{array}$ & $\begin{array}{c}.309 \\
(1.362)\end{array}$ \\
\hline $\begin{array}{l}\text { Deliberately given } \\
\text { alcohol/drugs to facilitate } \\
\text { intercourse }\end{array}$ & & & & & & $\begin{array}{l}1.312^{*} \\
(3.714)\end{array}$ & $\begin{array}{l}1.356^{*} \\
(3.880)\end{array}$ \\
\hline Education & & & & & & & \\
\hline $\begin{array}{l}\text { Have you attended a sexual } \\
\text { assault prevention class? }\end{array}$ & & & & & & & $\begin{array}{c}.229 \\
(1.257)\end{array}$ \\
\hline Constant & 1.500 & 1.510 & 1.343 & 2.037 & .216 & .794 & .826 \\
\hline Number of Cases & 161 & 161 & 160 & 157 & 156 & 151 & 146 \\
\hline -2 Log Likelihood & 216.360 & 216.335 & 215.168 & 200.044 & 196.193 & 179.351 & 171.012 \\
\hline
\end{tabular}

Note: Unstandardized logistic coefficients with odds ratios in parentheses

${ }^{a}=$ All others reference ${ }^{b}=$ Female identified as reference ${ }^{c}=$ All other places reference ${ }^{d}=$ All other relationships reference

$* \mathrm{p}<.05, * * \mathrm{p}<.01$ 


\begin{tabular}{|c|c|c|c|c|c|c|c|}
\hline Variable & $\begin{array}{l}\text { Model } \\
1\end{array}$ & $\begin{array}{l}\text { Model } \\
2\end{array}$ & $\begin{array}{l}\text { Model } \\
3 \\
\end{array}$ & $\begin{array}{l}\text { Model } \\
4\end{array}$ & $\begin{array}{l}\text { Model } \\
5\end{array}$ & $\begin{array}{l}\text { Model } \\
6\end{array}$ & $\begin{array}{l}\text { Model } \\
7\end{array}$ \\
\hline \multicolumn{8}{|l|}{ Gender } \\
\hline Male Identified $^{\text {a }}$ & $\begin{array}{l}-.960 * \\
(.383)\end{array}$ & $\begin{array}{l}-.966^{*} \\
(.381)\end{array}$ & $\begin{array}{l}-.999 * \\
(.368)\end{array}$ & $\begin{array}{l}-.712 \\
(.491)\end{array}$ & $\begin{array}{l}-.595 \\
(.552)\end{array}$ & $\begin{array}{l}-.440 \\
(.644)\end{array}$ & $\begin{array}{l}-.426 \\
(.653)\end{array}$ \\
\hline Non-binary ${ }^{\mathrm{b}}$ & & $\begin{array}{l}-.103 \\
(.902)\end{array}$ & $\begin{array}{l}-.105 \\
(.901)\end{array}$ & $\begin{array}{l}-.192 \\
(.825)\end{array}$ & $\begin{array}{l}-.254 \\
(.776)\end{array}$ & $\begin{array}{l}-.037 \\
(.964)\end{array}$ & $\begin{array}{l}-.068 \\
(.935)\end{array}$ \\
\hline Age & & & $\begin{array}{r}.050 \\
(1.052)\end{array}$ & $\begin{array}{r}.101 \\
(1.106)\end{array}$ & $\begin{array}{l}-.098 \\
(.906)\end{array}$ & $\begin{array}{l}-.317 \\
(.728)\end{array}$ & $\begin{array}{l}-.318 \\
(.728)\end{array}$ \\
\hline \multicolumn{8}{|l|}{ Place of Incidence } \\
\hline $\begin{array}{l}\text { Own } \\
\text { home/apartment/dorm }^{\mathrm{c}}\end{array}$ & & & & $\begin{array}{l}-.243 \\
(.785)\end{array}$ & $\begin{array}{l}-.240 \\
(.786)\end{array}$ & $\begin{array}{l}-.081 \\
(.922)\end{array}$ & $\begin{array}{r}-.082 \\
(.922)\end{array}$ \\
\hline $\begin{array}{l}\text { Other person's home/ } \\
\text { apartment/dorm }{ }^{c}\end{array}$ & & & & $\begin{array}{r}.147 \\
(1.159)\end{array}$ & $\begin{array}{r}.082 \\
(1.086)\end{array}$ & $\begin{array}{l}-.047 \\
(.954)\end{array}$ & $\begin{array}{l}-.061 \\
(.941)\end{array}$ \\
\hline \multicolumn{8}{|l|}{$\begin{array}{l}\text { Relationship to } \\
\text { perpetrator }\end{array}$} \\
\hline $\begin{array}{l}\text { Significant } \\
\text { Other/Date }\end{array}$ & & & & $\begin{array}{r}-1.056 * * \\
(.348)\end{array}$ & $\begin{array}{r}-1.071^{* *} \\
(.343)\end{array}$ & $\begin{array}{l}-.913 * \\
(.401)\end{array}$ & $\begin{array}{r}-.937 * \\
(.392)\end{array}$ \\
\hline Class Standing & & & & & $\begin{array}{c}.298 \\
(1.347)\end{array}$ & $\begin{array}{r}.396^{*} \\
(1.485)\end{array}$ & $\begin{array}{r}.396^{*} \\
(1.486)\end{array}$ \\
\hline \multicolumn{8}{|l|}{ Alcohol and/or Drugs } \\
\hline $\begin{array}{l}\text { Deliberately given } \\
\text { alcohol/drugs to } \\
\text { facilitate sex play }\end{array}$ & & & & & & $\begin{array}{c}.281 \\
(1.325)\end{array}$ & $\begin{array}{c}.309 \\
(1.362)\end{array}$ \\
\hline $\begin{array}{l}\text { Deliberately given } \\
\text { alcohol/drugs to } \\
\text { facilitate intercourse } \\
\text { Education }\end{array}$ & & & & & & $\begin{array}{l}1.392^{*} \\
(4.024)\end{array}$ & $\begin{array}{l}1.356^{*} \\
(3.880)\end{array}$ \\
\hline $\begin{array}{l}\text { Have you attended a } \\
\text { sexual assault } \\
\text { prevention class? }\end{array}$ & & & & & & & $\begin{array}{l}.229 \\
(1.257)\end{array}$ \\
\hline Constant & 1.469 & 1.478 & 1.358 & 1.983 & 1.292 & .875 & .826 \\
\hline -2 Log Likelihood & 196.014 & 195.997 & 195.910 & 184.727 & 181.986 & 171.332 & 171.012 \\
\hline
\end{tabular}

Note: Unstandardized logistic coefficients with odds ratios in parentheses

${ }^{a}=$ All others reference ${ }^{b}=$ Female identified as reference ${ }^{c}=$ All other places reference ${ }^{d}=$ All other relationships reference

$* \mathrm{p}<.05, * * \mathrm{p}<.01$ 


\section{References:}

Ahrens, Courtney E. 2006. "Being Silenced: The Impact of Negative Social Reactions on the Disclosure of Rape." American Journal of Community Psychology 38(3-4):26374.

Ahrens, Courtney E. and Erendira Aldana. 2012. "The Ties That Bind: Understanding the Impact of Sexual Assault Disclosure on Survivors' Relationships with Friends, Family, and Partners." Journal of Trauma \& Dissociation : The Official Journal of the International Society for the Study of Dissociation (ISSD) 13(2):226-43.

Ahrens, Courtney E., Rebecca Campbell, N. Karen Ternier-Thames, Sharon M. Wasco, and Tracy Sefl. 2007. "Deciding Whom To Tell: Expectations and Outcomes of Rape Survivors' First Disclosures.” Psychology of Women Quarterly 31(1):38-49.

Ahrens, Courtney E., Janna Stansell, and Amy Jennings. 2010. "To Tell or Not to Tell: The Impact of Disclosure on Sexual Assault Survivors' Recovery." Violence and Victims 25(5):631-48.

Ali, Russlynn. 2011. "Dear Colleague Letter from Assistant Secretary for Civil Rights Russlynn Ali." 19.

Allen, Christopher T., Rebecca Ridgeway, and Suzanne C. Swan. 2015. "College Students' Beliefs Regarding Help Seeking for Male and Female Sexual Assault Survivors: Even Less Support for Male Survivors." Journal of Aggression, Maltreatment \& Trauma 24(1):102-15.

Armstrong, Elizabeth A., Laura Hamilton, and Brian Sweeney. 2006. "Sexual Assault on Campus : A Multilevel, Integrative Approach to Party Rape." Social Problems 53(4):483-99.

Association of Title IX. Administrators. 2013. Mandatory Reporters: A Policy for Faculty and Professional Staff. Vol. 7858. Malvern, PA.

Bannon, R. Sean, Matthew W. Brosi, and John D. Foubert. 2013. "Sorority Women's and Fraternity Men's Rape Myth Acceptance and Bystander Intervention Attitudes." Journal of Student Affairs Research and Practice 50(1):72-87.

Bannon, R. Sean, Matthew W. Brosi, John D. Foubert, Martha R. Burt, Rochelle Semmel Albin, and Sarah McMahon. 2013. "Rape Myths in Review Lonsway 1994.Pdf." Journal of Personality and Social Psychology 22(3):72-87.

Banyard, Victoria L. 2014. "Improving College Campus-Based Prevention of Violence Against Women.” Trauma, Violence, \& Abuse 15(4):339-51.

Banyard, Victoria L., Elizabeth G. Plante, Ellen S. Cohn, Cari Moorhead, Sally K. Ward, and Wendy Walsh. 2005. "Revisiting Unwanted Sexual Experiences on Campus: A 12-Year Follow-Up." Violence against Women 11(4):426-46.

Banyard, Victoria L., Sally Ward, E. S. Cohn, E. G. Plante, C. Moorhead, and W. Walsh. 
2007. "Unwanted Sexual Contact on Campus: A Comparison of Women's and Men's Experiences.” Violence and Victims 22(1):52-70.

Barchenger, Stacey and Joey Garrison. 2015. "Vanbderbilt Rape Trial: Defendants Found Guilty on All Charges." USA Today. Retrieved September 3, 2015 (http://www.usatoday.com/story/sports/ncaaf/sec/2015/01/27/vanderbilt-playersverdict-guilty-rape-vandenburg-batey/22430567/).

Beaulieu, Mark, Creaig Dunton, LaVerne McQuiller Williams, and Judy L. Porter. 2017. "The Impact of Sexual Orientation on College Student Victimization: An Examination of Sexual Minority and Non-Sexual Minority Student Populations.” Psychology 08(11):1728-47.

Benson, Brenda J., Carol L. Gohm, and Alan M. Gross. 2007. "College Women and Sexual Assault: The Role of Sex-Related Alcohol Expectancies." Journal of Family Violence 22(6):341-51.

Benson, Dennis, Catherine Charlton, and Fern Goodhart. 1992. "Acquaintance Rape on Campus: A Literature Review." Journal of American College ... 40(4):157-65.

Bierie, David M. and James C. Davis-Siegel. 2015. "Measurement Matters: Comparing Old and New Definitions of Rape in Federal Statistical Reporting." Sexual Abuse: Journal of Research and Treatment 27(5):443-59.

Bletzer, Keith V and Mary P. Koss. 2004. "Narrative Constructions of Sexual Violence as Told by Female Rape Survivors in Three Populations of the Southwestern United States: Scripts of Coercion, Scripts of Consent." Medical Anthropology 23(2):11356.

Boyle, Kaitlin M. 2015. "Social Psychological Processes That Facilitate Sexual Assault within the Fraternity Party Subculture.” Sociology Compass 9(5):386-99.

Brake, Deborah L. 2017. "Back To Basics: Excavating the Sex Discrimination Roots of Campus Sexual Assault.” Tennessee Journal of Race, Gender, \& Social Justice $6(1): 7-40$.

Branch, Kathryn A. and Tara N. Richards. 2013. "The Effects of Receiving a Rape Disclosure: College Friends' Stories.” Violence against Women 19(5):658-70.

Brown, Sarah and Katherine Mangan. 2018. "What You Need to Know About the Proposed Title IX Regulations." Chronicle of Higher Education 65(12):17.

Brubaker, Sarah Jane. 2009. "Sexual Assault Prevalence, Reporting and Policies: Comparing College and University Campuses and Military Service Academies." Security Journal 22(1):56-72.

van der Bruggen, Madeleine and Amy Grubb. 2014. "A Review of the Literature Relating to Rape Victim Blaming: An Analysis of the Impact of Observer and Victim Characteristics on Attribution of Blame in Rape Cases." Aggression and Violent Behavior 19(5):523-31. 
Bureau of Justice Statistics. 2014. "National Crime Victimization Survey." Retrieved (http://www.bjs.gov/index.cfm?ty=nvat).

Burnett, Ann, Jody L. Mattern, Liliana L. Herakova, David H. Kahl, Cloy Tobola, and Susan E. Bornsen. 2009. "Communicating/Muting Date Rape: A Co-Cultural Theoretical Analysis of Communication Factors Related to Rape Culture on a College Campus." Journal of Applied Communication Research 37(4):465-85.

Burt, Martha R. 1980. “Cultural Myths and Supports for Rape.” Journal of Personality and Social Psychology 38(2):217-30.

Burt, Martha R. 1991. "Rape Myths.” Pp. 129-44 in Confronting Rape \& Sexual Assault, edited by M. E. Odem and J. Clay-Warner. Willmington, DE: Scholarly Resources Inc.

Burt, Martha R. and Rochelle Semmel Albin. 1981. "Rape Myths, Rape Definitions, and Probability of Conviction." Journal of Applied Social Psychology 11(3):212-30.

California State Law. 2014. "Senate Bill No. 967."

Carey, Kate B., Sarah E. Durney, Robyn L. Shepardson, Michael P. Carey, Shannan Catalano, Michele Harmon, Allen Beck, David Cantor, Jennifer M. Gómez, Marina N. Rosenthal, Carly P. Smith, and Jennifer J. Freyd. 2015. "Incapacitated and Forcible Rape of College Women: Prevalence across the First Year." Journal of Adolescent Health 56(6):678-80.

Carroll, Marjorie H., Judith E. Rosenstein, John D. Foubert, M. Diane Clark, and Lisa M. Korenman. 2016. "Rape Myth Acceptance: A Comparison of Military Service Academy and Civilian Fraternity and Sorority Students." Military Psychology 28(5):306-17.

Cleere, Colleen and Steven Jay Lynn. 2013. "Acknowledged versus Unacknowledged Sexual Assault among College Women." Journal of Interpersonal Violence 28(12):2593-2611.

Coulter, Robert W. S., Christina Mair, Elizabeth Miller, John R. Blosnich, Derrick D. Matthews, and Heather L. McCauley. 2017. "Prevalence of Past-Year Sexual Assault Victimization Among Undergraduate Students: Exploring Differences by and Intersections of Gender Identity, Sexual Identity, and Race/Ethnicity." Prevention Science 18(6):726-36.

Cox, Caroline. 2018. "Saving Title IX Values: The Campus SaVE Act as a Critical Tool for Survivors and Allies." Harvard Journal of Law \& Gender 41:429-50.

DeMatteo, David, Meghann Galloway, Shelby Arnold, and Unnati Patel. 2015. "Sexual Assault on College Campuses: A 50-State Survey of Criminal Sexual Assault Statutes and Their Relevance to Campus Sexual Assault." Psychology, Public Policy, and Law 21(3):227-38.

Deming, Michelle E., Eleanor Krassen Covan, Suzanne C. Swan, and Deborah L. 
Billings. 2013. "Exploring Rape Myths, Gendered Norms, Group Processing, and the Social Context of Rape among College Women: A Qualitative Analysis." Violence against Women 19(4):465-85.

Donat, Patricia L. N. and John D'Emilio. 1992. "A Feminist Redefinition of Rape and Sexual Assault: Historical Foundations and Change." Journal of Social Issues 48(1):9-22.

Donde, Sapana D., Sally K. A. Ragsdale, Mary P. Koss, and Alyssa N. Zucker. 2018. "If It Wasn't Rape, Was It Sexual Assault? Comparing Rape and Sexual Assault Acknowledgment in College Women Who Have Experienced Rape." Violence Against Women 24(14):1718-38.

Downing-Matibag, Teresa M. and Brandi Geisinger. 2009. "Hooking up and Sexual Risk Taking among College Students: A Health Belief Model Perspective." Qualitative Health Research 19(9):1196-1209.

Dunn, P. C., K. Vail-Smith, and S. M. Knight. 1999. "What Date/Acquaintance Rape Victims Tell Others: A Study of College Student Recipients of Disclosure." Journal of American College Health : J of ACH 47(5):213-19.

Edwards, Sarah R., Kathryn A. Bradshaw, and Verlin B. Hinsz. 2014. "Denying Rape but Endorsing Forceful Intercourse: Exploring Differences Among Responders." Violence and Gender 1(4):188-93.

FBI. 2017. "Uniform Crime Reporting Statistics.” Retrieved April 23, 2018 (https://www.ucrdatatool.gov/Search/Crime/State/RunCrimeStatebyState.cfm).

Felson, RB and PP Paré. 2005. "The Reporting of Domestic Violence and Sexual Assault by Nonstrangers to the Police." Journal of Marriage and Family 67(August):597610.

Fisher, Bonnie S., Francis T. Cullen, Michael G. Turner, and Mary Lou Leary. 2000. "The Sexual Victimization of College Women." United States Department of Justice: National Institute of Justice.

Fisher, Bonnie S., Leah E. Daigle, Francis T. Cullen, and Michael G. Turner. 2003. "Reporting Sexual Victimization To The Police And Others: Results From a National-Level Study of College Women." Criminal Justice and Behavior 30(1):638.

Flack, William F., Kimberly A. Daubman, Marcia L. Caron, Anna T. Hall, and Erin R. Stine. 2007. "Risk Factors and Consequences of Unwanted Sex Among University Students: Hooking Up, Alcohol, and Stress Response.” Journal of Interpersonal Violence 22(2):139-57.

Flack, William F, Kimberly A. Daubman, Marcia L. Caron, Anna T. Hall, and Erin R. Stine. 2007. "Risk Factors and Hooking Up, Alcohol , and Stress Response." Journal of Interpersonal Violence 55(5):139-57. 
Forde, Kaelyn. 2014. "Carrying That Weight: Students Protest Campus 'Rape Culture.'” Aljazeera America. Retrieved September 3, 2015

(http://america.aljazeera.com/articles/2014/10/30/columbia-sexualviolenceprotest.html).

Franklin, Cortney a. 2010. "Physically Forced, Alcohol-Induced, and Verbally Coerced Sexual Victimization: Assessing Risk Factors among University Women." Journal of Criminal Justice 38(2):149-59.

Freyd, Jennifer J. 2014. Campus Sexual Assault and Institutional Betrayal.

Gannon, Susanne and Bronwyn Davies. 2007. "Postmodern, Poststructural, and Critical Theories." Pp. 71-106 in Handbook of Feminist Research: Theory and Praxis, edited by S. N. Hesse-Biber. Thousand Oaks, CA: Sage Publications, Inc.

Giraldi, Ashley and Elizabeth Monk-Turner. 2017. "Perception of Rape Culture on a College Campus: A Look at Social Media Posts.” Women's Studies International Forum 62:116-24.

Guerette, Sarah M. and Sandra L. Caron. 2008. "Assessing the Impact of Acquaintance Rape.” Journal of College Student Psychotherapy 22(2):37-41.

Haaken, Janice. 2017. "Many Mornings After: Campus Sexual Assault and Feminist Politics." Family Relations 66(1):17-28.

Harber, Kent D., Peter Podolski, and Christian H. Williams. 2015. "Emotional Disclosure and Victim Blaming." Emotion 15(5):603-14.

Hawkesworth, Mary E. 1989. "Knowers, Knowing, Known: Feminist Theory and Claims of Truth.” Signs 14(3):533-57.

Hayes, R. M., R. L. Abbott, and S. Cook. 2016. "Its Her Fault: Student Acceptance of Rape Myths On Two College Campuses.” Violence Against Women 1-16.

Heldman, Caroline and Lisa Wade. 2010. "Hook-Up Culture: Setting a New Research Agenda." Sexuality Research and Social Policy 7(4):323-33.

Hockett, Jericho M., Donald A. Saucier, and Caitlyn Badke. 2016. "Rape Myths, Rape Scripts, and Common Rape Experiences of College Women: Differences in Perceptions of Women Who Have Been Raped." Violence against Women 22(3):307-23.

Holton, Gerald. 2004. "Robert K . Merton , 4 July 1910 - 23 February 2003." Proceedings of the American Philosophical Society 148(4):505-17.

Howle, Elaine M. and Doug Cordiner. 2013. Sexual Harrassment and Sexual Violence: California Universities Must Better Protect Students by Doing More to Prevent, Respond to, and Resolve Incidents. Sacramento.

Iverson, Susan V. 2016. “A Policy Discourse Analysis of Sexual Assault Policies in 
Higher Education.” Pp. 15-32 in The crisis of campus sexual violence: Critical perspectives on prevention and response, edited by S. Carrigan Wooten and R. W. Mitchell. New York: Routledge.

Johnson, Allan G. 1997. The Gender Knot: Unraveling Out Patriarchal Legacy. Philadelphia, PA: Temple University Press.

Johnson, Allan Griswold. 1980. "On the Prevalence of Rape in the United States." Signs 6(1):136-46.

Jozkowski, Kristen N. and Jacquelyn D. Wiersma-Mosley. 2017. “The Greek System: How Gender Inequality and Class Privilege Perpetuate Rape Culture.” Family Relations 66(1):89-103.

Kahn, Arnold S., Jennifer Jackson, Christine Kully, Kelly Badger, and Jessica Halvorsen. 2003. "Calling It Rape: Differences in Experiences of Women Who Do or Do Not Label Their Sexual Assault as Rape." Psychology of Women Quarterly 27(3):23342.

Kalish, Rachel and Michael Kimmel. 2011. "Hooking Up: Hot Hetero Sex or the New Numb Narrative?" Australian Feminist Studies 26(67):137-51.

Kaysen, Debra, Clayton Neighbors, Joel Martell, Nicole Fossos, and Mary E. Larimer. 2006. "Incapacitated Rape and Alcohol Use: A Prospective Analysis." Addictive Behaviors 31(10):1820-32.

Kilpatrick, Dean G., Heidi S. Resnick, Kenneth J. Ruggiero, Lauren M. Conoscenti, and Jenna L. McCauley. 2007. Drug-Facilitated, Incapacitated, and Forcible Rape: A National Study. Charleston.

Kolivas, Elizabeth D. and Alan M. Gross. 2007. “Assessing Sexual Aggression: Addressing the Gap between Rape Victimization and Perpetration Prevalence Rates." Aggression and Violent Behavior 12(3):315-28.

Koo, Kelly H., Hong V. Nguyen, Michele P. Andrasik, and William H. George. 2015. "The Cultural Context of Nondisclosure of Alcohol-Involved Acquaintance Rape Among Asian American College Women: A Qualitative Study.” The Journal of Sex Research 52(1):55-68.

Koss, Mary P. 2011. "Hidden, Unacknowledged, Acquaintance, and Date Rape: Looking Back, Looking Forward." Psychology of Women Quarterly 35(2):348-54.

Koss, Mary P. 1998. "Hidden Rape: Sexual Agression and Victimization in a National Sample of Students in Higher Education." Pp. 51-69 in Confronting Rape \& Sexual Assault, edited by M. E. Odem and J. Clay-Warner. Willmington, DE: Scholarly Resources Inc.

Koss, Mary P. and Cheryl J. Oros. 1982. "Sexual Experiences Survey: A Research Instrument Investigating Sexual Aggression and Victimization." Journal of Consulting and Clinical Psychology 50(3):455-57. 
Krakauer, Jon. 2015. Missoula: Rape and The Justice System in a College Town. New York: Doubleday.

Krebs, Christopher P., Christine H. Lindquist, Warner D. Tara, Bonnie S. Fisher, and Sandra L. Martin. 2007. The Campus Sexual Assault (CSA) Study.

Lambert, Tracy A., Arnold S. Kahn, and Kevin J. Apple. 2003. "Pluralistic Ignorance and Hooking Up." Journal of Sex Research 40(2):129-33.

Lindquist, Christine H., Sandra L. Martin, Christopher P. Krebs, Tara D. Warner, and Bonnie S. Fisher. 2009. “College Women's Experiences with Physically Forced, Alcohol- or Other Drug-Enabled and Drug-Facilitated Sexual Assault Before and Since Entering College." Journal of American College Health 57(6):639-47.

Littleton, Heather L. and Danny Axsom. 2003. "Rape and Seduction Scripts of University Students: Implications for Rape Attributions and Unacknowledged Rape." Sex Roles 49(9-10):465-75.

Littleton, Heather L., Danny Axsom, Carmen Radecki Breitkopf, and Abbey Berenson. 2006. "Rape Acknowledgment and Postassault Experiences: How Acknowledgement Status Relates to Disclosure, Coping, Worldview, and Reactions Received From Others." Violence and Victims 21(6):761-78.

Littleton, Heather, Holly Tabernik, Erika J. Canales, and Tamika Backstrom. 2009. "Risky Situation or Harmless Fun? A Qualitative Examination of College Women's Bad Hook-up and Rape Scripts." Sex Roles 60(11-12):793-804.

Maloney, Carolyn and Robert Jr. Casey. 2013. Campus Sexual Violence Elimination Act. Washington D.C.: Untied States Senate.

Marcus, Sharon. 1992. "Fighting Bodies, Fighting Words: A Theory and Politics of Rape Prevention." Feminist Theorize the Political 385-403.

Martin, Patricia Yancey. 2016. "The Rape Prone Culture of Academic Contexts: Fraternities and Athletics." Gender \& Society 30(1):30-43.

McCray, Kristy L. 2015. "Intercollegiate Athletes and Sexual Violence." Trauma, Violence, \& Abuse 16(4):438-43.

McMahon, Sarah. 2007. “Understanding Community-Specific Rape Myths.” Affilia 22(4):357-70.

Menegatos, Lisa, Linda C. Lederman, and Aaron Hess. 2010. “Friends Don't Let Jane Hook Up Drunk: A Qualitative Analysis of Participation in a Simulation of College Drinking-Related Decisions." Communication Education 59(3):374-88.

Merton, RK. 1987. "Three Fragments from a Sociologist's Notebooks: Establishing the Phenomenon, Specified Ignorance, and Strategic Research Materials.” Annual Review of Sociology 13:1-28. 
Messman-Moore, Terri L., Aubrey A. Coates, Kathryn J. Gaffey, and Carrie F. Johnson. 2008. "Sexuality, Substance Use, and Susceptibility to Victimization: Risk for Rape and Sexual Coercion in a Prospective Study of College Women." Journal of Interpersonal Violence 23(12):1730-46.

Miranda, Robert, Lori A. Meyerson, Patricia J. Long, Brian P. Marx, and Sharon M. Simpson. 2002. "Sexual Assault and Alcohol Use: Exploring the Self-Medication Hypothesis.” Violence and Victims 17(2):205-17.

Mohler-Kuo, Meichun, George W. Dowdall, Mary P. Koss, and Henry Wechsler. 2004. "Correlates of Rape While Intoxicated in a National Sample of College Women." Journal of Studies on Alcohol 65(1):37-45.

Moore, Andrea. 2014. "Reframing Sexual Responsibility: Hooking-up Reframing Sexual Responsibility: Hooking-Up.” Dissenting Voices 3(1):51-63.

Moore, Briana M. and Thomas Baker. 2016. “An Exploratory Examination of College Students Likelihood of Reporting Sexual Assault to Police and University Officials: Results of a Self-Report Survey." Journal of Interpersonal Violence.

Moors, Rosetta and Ruth Webber. 2012. "The Dance of Disclosure: Online SelfDisclosure of Sexual Assault.” Qualitative Social Work 12(6):799-815.

Morgan, Rachel and Grace Kena. 2017. "Criminal Victimization, 2016 - Summary." Bureau of Justice Statistics 2016(December):1-24.

Mouilso, Emily R., Sarah Fischer, and Karen S. Calhoun. 2012. "A Prospective Study of Sexual Assault and Alcohol Use Among First-Year College Women." Violence and Victims 27(1):78-95.

Muehlenhard, Charlene L., Zoë D. Peterson, Terry P. Humphreys, and Kristen N. Jozkowski. 2017. "Evaluating the One-in-Five Statistic: Women's Risk of Sexual Assault While in College." Journal of Sex Research 54(4-5):549-76.

Nabors, Erin L. and Jana L. Jasinski. 2009. “Intimate Partner Violence Perpetration Among College Students: The Role of Gender Role and Gendered Violence Attitudes." Feminist Criminology 4(1):57-82.

Ollen, Elizabeth W., Victoria E. Ameral, Kathleen Palm Reed, and Denise A. Hines. 2017. "Sexual Minority College Students' Perceptions on Dating Violence and Sexual Assault.” Journal of Counseling Psychology 64(1):112-19.

Orchowski, Lindsay M. and Christine A. Gidycz. 2015. "Psychological Consequences Associated With Positive and Negative Responses to Disclosure of Sexual Assault Among College Women: A Prospective Study." Violence Against Women 21(7):803-23.

Orchowski, Lindsay M. and Christine A. Gidycz. 2012. "To Whom Do College Women Confide Following Sexual Assault? A Prospective Study of Predictors of Sexual Assault Disclosure and Social Reactions". Violence Against Women 18(3):264-88 
Orchowski, Lindsay M., Amy S. Untied, and Christine A. Gidycz. 2013. "Factors Associated with College Women's Labeling of Sexual Victimization." Violence and Victims 28(6):940-58.

Oregon State Law. 2011. “OregonLaws.Org.” Retrieved (http://www.oregonlaws.org/ors/163.305).

Oregon University System. n.d. Policy on Sexual Misconduct.

Paul, Lisa a, Kate Walsh, Jenna L. McCauley, Kenneth J. Ruggiero, Heidi S. Resnick, and Dean G. Kilpatrick. 2013. "College Women's Experiences with Rape Disclosure: A National Study.” Violence against Women 19(4):486-502.

Peterson, Zoë D. and Charlene L. Muehlenhard. 2004. "Was It Rape the Function of Women's Rape Myth Acceptance and Definitions of Sex in Labeling Their Own Experiences." Sex Roles 51(3-4):129-44.

Peterson, Zoë D. and Charlene L. Muehlenhard. 2007. "Conceptualizing the 'Wantedness' of Women's Consensual and Nonconsensual Sexual Experiences: Implications for How Women Label Their Experiences with Rape.” Journal of Sex Research 44(1):72-88.

Potter, Sharyn J., Kim Fountain, and Jane G. Stapleton. 2012. "Addressing Sexual and Relationship Violence in the LGBT Community Using a Bystander Framework." Harvard Review of Psychiatry 20(4):201-8.

Public Law 113-4. 2013. Violence Against Women Reauthorization Act of 2013.

Reling, Timothy T., Michael S. Barton, Sarah Becker, and Matthew A. Valasik. 2017. "Rape Myths and Hookup Culture: An Exploratory Study of U.S. College Students' Perceptions." Sex Roles 1-14.

Rickert, Vaughn I., Constance M. Wiemann, and Roger D. Vaughan. 2005. "Disclosure of Date/Acquaintance Rape: Who Reports and When." Journal of Pediatric and Adolescent Gynecology 18(1):17-24.

Ryan, Kathryn M. 2011. "The Relationship between Rape Myths and Sexual Scripts: The Social Construction of Rape.” Sex Roles 65(11-12):774-82.

Sable, Marjorie, Fran Danis, Denise L. Mauzy, and Sarah K. Gallagher. 2006. "Barriers to Reporting Sexual Assault for Women and Men: Perspectives of College Students." Journal of American College Health 55(3):157-62.

Sanday, Peggy Reeves. 1996. "Rape-Prone Versus Rape-Free Campus Cultures." Violence Against Women 2(2):191-208.

Sanday, Peggy Reeves. 2007. Fraternity Gang Rape: Sex, Brotherehood, and Privilege on Campus. Second. New York: New York University Press.

Schwartz, Martin D. and Molly S. Leggett. 1999. "Bad Dates or Emotional Trauma? The 
Aftermath of Campus Sexual Assault." Violence Against Women 5(3):251-71.

Schwartz, Martin D. and Carol A. Nogrady. 1996. "Fraternity Membership, Rape Myths, and Sexual Aggression on a College Campus." Violence Against Women 2(2):14862.

Sims, Calvin M., Nora E. Noel, and Stephen a Maisto. 2007. "Rape Blame as a Function of Alcohol Presence and Resistance Type." Addictive Behaviors 32(12):2766-75.

Sinozich, Sofi, Lynn Langton, Rebecca L. Stotzer, Danielle Maccartney, Myron B. Thompson, Kristy L. McCray, Sofi Sinozich, and Lynn Langton. 2014. Rape and Sexual Assault: Victimization Among College-Age Females, 1994-2013. Vol. 16.

Smith, Tovia. 2018. "Trump Administration Defends Campus Sexual Assault Rules." National Public Radio. Retrieved (https://www.npr.org/2018/07/20/630742928/trump-administration-defends-campussexual-assault-rules).

Southern Oregon University. 2014. Campus Report on Sexual Misconduct.

Southern Oregon University. 2016. Enrollment Report for Spring 2015 Enrollment Report for Spring 2015 Student Credit Hours ( SCH ).

Streng, Tara K. and Akiko Kamimura. 2017. "Perceptions of University Policies to Prevent Sexual Assault on Campus Among College Students in the USA." Sexuality Research and Social Policy 14(2):133-42.

Suk Gersen, Jeannie. 2017. "Betsy DeVos, Title IX, and the 'Both Sides' Approach to Sexual Assault." The New Yorker, September, 1-5.

Süssenbach, Philipp, Friederike Eyssel, Jonas Rees, and Gerd Bohner. 2017. "Looking for Blame: Rape Myth Acceptance and Attention to Victim and Perpetrator." Journal of Interpersonal Violence 32(15):2323-44.

Sutton, Tara E. and Leslie Gordon Simons. 2014. "Sexual Assault Among College Students: Family of Origin Hostility, Attachment, and the Hook-Up Culture as Risk Factors." Journal of Child and Family Studies 24(10):2827-40.

The White House Task Force to Protect Students From Sexual Assault. 2014. Not Alone: The First Report of the White House Task Force to Protect Students From Sexual Assault.

Tolentino, Jia. 2018. "Is There a Smarter Way to Think about Sexual Assault on Campus?" The New Yorker, February, 1-18.

U.S. Federal Bureau of Investigation. 2013. "Uniform Crime Reporting Statistics." Retrieved (http://www.ucrdatatool.gov/Search/Crime/State?RunCrimeTrendsInOneVar.cfm).

Untied, Amy S., Lindsay M. Orchowski, and Vanessa Lazar. 2013. “College Men’s and 
Women's Respective Perceptions of Risk to Perpetrate or Experience Sexual Assault: The Role of Alcohol Use and Expectancies." Violence against Women 19(7):903-23.

White, Jacquelyn, Paige Hall Smith, and John A. Humphrey. 2001. Longitudinal Study of Violence against Women: Victimization and Perpetration among College Students in a State-Supported University in the United States, .

Wiersma-Mosley, Jacquelyn and James DiLoreto. 2018. "The Role of Title IX Coordinators on College and University Campuses." Behavioral Sciences 8(4):38.

Wolitzky-Taylor, Kate B., Heidi S. Resnick, Ananda B. Amstadter, Jenna L. McCauley, Kenneth J. Ruggiero, and Dean G. Kilpatrick. 2011. "Reporting Rape in a National Sample of College Women." Journal of American College Health : J of ACH 59(7):582-87.

Wood, Julia T. 2008. "Critical Feminist Theories: Giving Voice and Visibility to Women's Experiences in Interpersonal Communication." Pp. 323-34 in Engaging Theories in Interpersonal Communication: Multiple Perspectives, edited by D. O. Braithwaite and L. A. Baxter. Thousand Oaks, CA: Sage Publications, Inc.

Yung, Corey Rayburn. 2015. “Concealing Campus Sexual Assault: An Empirical Examination." Psychology, Public Policy, and Law 21(1):1-9.

Zinzow, Heidi M. and Martie Thompson. 2011. "Barriers to Reporting Sexual Victimization: Prevalence and Correlates among Undergraduate Women.” Journal of Aggression, Maltreatment \& Trauma 20(7):711-25. 
Appendix A: Informed Consent

\section{INFORMED CONSENT}

You are invited to participate in a study about sexual behavior and sexual assault conducted by Whitney Head-Burgess, a graduate student in the Department of Sociology at Portland State University under the direction of Dr. Matt Carlson at Portland State University and in partnership with the Southern Oregon University Women's Resource Center. The purpose of this study is to examine students' experiences with sex, sexual assault and disclosure/reporting.

The results of the survey will provide important information about sexual assault on campus and help the Southern Oregon University Women's Resource Center assess the incidences of sexual assault within the campus community in an effort to provide meaningful programming to combat sexual assault. Since this survey will ask a number of questions which could make you feel uncomfortable or experience some anxiety, a list of resources will be provided to you at the end of the survey should you feel that you require professional guidance.

Benefits of participation in this survey include playing an integral role in reporting the true incidence of sexual assault and coercion on campus which could influence future policy and training regarding sexual assault and misconduct. 
This research is in no way affiliated with Facebook or any marketing or advertising entity. No personal information will be collected. All information is strictly anonymous and will be protected to the degree permitted by the technology used.

Only group data will be reported, and the analysis will include only aggregate data. Results will be statistically compiled. No names or identifying characteristics will ever be used in any report of the results of this study. The aggregate data will be analyzed and may be presented at professional conferences to help further research in the field of sociology and criminology.

Your participation is voluntary; you have the option not to respond to any of the questions. You may stop taking the survey at any time by closing your web browser. Participation or nonparticipation will not impact your relationship with Southern Oregon University or Portland State University. The survey should take about 15 minutes to complete.

If you have concerns or problems about your participation in this study or your rights as a research subject, please contact the Human Subjects Research Review Committee, Office of Research and Sponsored Projects, Portland State University at (503)725-3423. If you have questions about the study itself, contact Whitney Head-Burgess at (541) 8405809.

Please print a copy of this page for your personal records. 
By continuing, you are confirming that you are at least 18 years old and are giving your informed consent to participate in the study. 
Appendix B: Survey Introduction

What is the purpose of this research?

We are asking you to participate in this research because Southern Oregon University Women's Resource Center, in partnership with Portland State University Master's student, Whitney Head-Burgess are trying to learn more about the prevalence of and risk factors surrounding sexual assault at Southern Oregon University. Further, we are interested in why victims may choose to disclose the event to friends, family, clergy, etc. instead of reporting it to the authorities.

How much time will it take?

The survey should take ten to fifteen minutes.

What will I be asked to do if I agree to participate?

The survey will ask you a set of questions regarding any experiences of unwanted sexual contact during your time at SOU. We will also be asking some general personal information such as age, racial or ethnic identity, gender identity, class standing, sexual identity and alcohol consumption.

What are the risks involved in participating in this study?

The survey contains questions about experiences of unwanted sexual contact and sensitive topics like alcohol and drug use. Answering some of these questions may trigger or upset you or make you feel uncomfortable. We will provide with a list of resources you can contact if you feel upset, at the end of the survey. 
What are the benefits of my participation in this study?

While you may not benefit personally from completing the survey, your answers are very important in helping gauge the incidence of sexual assault and violence on campus. Further, your responses will help SOU to better prevent sexual assault and provide assistance to survivors.

Can I decide not to participate?

Yes, you can choose to not participate. Even if you decide to take the survey, you can change your mind and leave the survey without any negative consequences.

How will the anonymity of the research records be protected?

This study is completely anonymous, and there is no way for the researcher or anyone else to connect the answers you give with your identity. As a further privacy measure, IP addresses associated with the survey will be permanently deleted before analysis. 
Appendix C: Survey Instrument

1. What gender do you identify as?

Female $\quad \square$ Male $\square$ Transgender $\square$ Other (space to write in, if desired)

2. What is your age?

3. Would you describe yourself as: (mark all that apply)
Native American
Asian
Black/African American
Hispanic/Latino/a
Pacific Islander
White/Caucasian
Other:

4. What is your academic standing at SOU?

Freshman (0-44 credits)

Sophomore (45-89 credits)

Junior (90-134 credits)

Senior (165 credits or more)

Post-baccalaureate

5. How do primarily take your classes at SOU?

On campus $\square$ Online

Alcohol Consumption Questions

It is well known that college students often drink in social situations. In the next set of questions, we'd like to know a little bit about your personal drinking habits. Remember that your responses will be kept anonymous.

6. How often do you drink alcohol?

I never drink or have not drunk since the beginning of this school year

I drink less than once a month, but have at least once since the school year started

I drink 1 to 3 times a month

I drink 1 to 2 times a week

I drink more than 2 times a week

7. How many times have you become drunk or pretty high in the average month since the school year started?

Never

One time

2 to 5 times

6 to 9 times

10 or more times

8. Where do you normally drink, when you drink? Please choose all that apply.

At your own home

At a party

At a pub, bar or restaurant 
At someone else's home/apartment

Other:

\section{Consensual Sex Questions}

For the purposes of this section, sexual intercourse will be defined as vaginal, oral or anal sex; this includes penetration by a penis, object, tongue, finger, or oral copulation no matter how slight.

9. Have you ever had sexual intercourse with another person when you both wanted to?
Yes
$\square$ No
$\square$ Decline to answer

10. Have you ever had someone misinterpret the level of sexual intimacy you desired, that is, have you ever engaged in consensual unwanted sex?
Yes
$\square$ No
Decline to answer

Sexual coercion questions

For the purpose of these questions, sex play will be defined as kissing, fondling or petting but not intercourse.

11. Have you ever given in to sex play when you didn't want to because you were overwhelmed by the other person's continual arguments and pressure?
Yes
$\square$ No
$\square$ Decline to answer

12. Have you ever engaged in sex play when you didn't want to because the other person used their position of authority (boss, teacher, supervisor) to make you?
Yes
$\square$ No
$\square$ Decline to answer

13. Have you ever engaged in sex play when you didn't want to because the other person threatened physical force (twisting your arm, holding you down, etc.)?

Yes

$\square$ No

Decline to answer

14. Have you ever had someone attempt sexual intercourse when you didn't want to by threatening or using some degree of force but intercourse did not occur?
Yes
$\square$ No
Decline to answer

15. Has anyone ever deliberately given you alcohol or drugs and attempted to engage in sexual intercourse when you didn't want to, but intercourse did not occur?

Yes $\quad \square$ No $\quad \square$ Decline to answer

Sexual assault questions

For the purposes of this section, sexual assault will be defined as: coerced sex play, coerced attempted intercourse, coerced intercourse and forced intercourse, including rape.

Oregon law defines sexual assault as any unwanted sexual contact, and the official definition encompasses much more that the traditional, cultural understanding of rape. 
Further, the law takes into consideration mental and physical incapacitation including incapacitation caused by alcohol or drugs, which would impede one person's ability to relay messages of explicit consent.

16. Have you ever given in to sexual intercourse when you didn't want to because you were overwhelmed by the other person's continual arguments and pressure?
Yes
$\square$ No
Decline to answer

17. Have you ever engaged in sexual intercourse when you didn't want to because the other person used their position of authority (boss, teacher, supervisor) to make you?
Yes
$\square$ No
Decline to answer

18. Have you ever engaged in sexual intercourse when you didn't want to because the other person threatened physical force (twisting your arm, holding you down, etc.)?

$$
\text { Yes } \quad \square \text { No } \quad \square \text { Decline to answer }
$$

19. Have you ever had someone have sexual intercourse with you when you didn't want to by threatening or using some degree of force?
Yes
$\square$ No
$\square$ Decline to answer

20. Has anyone ever deliberately given you alcohol or drugs and engage in sexual intercourse with you when you didn't want to?

Yes $\square$ No

Decline to answer

Disclosure and situational questions:

These questions are in regard to the experiences listed on the previous pages involving the most recent incidence of unwanted sex play and unwanted sexual intercourse.

21. Did you know the other person involved?

Yes, very well

Yes, not well

No

22. What was the nature of your relationship to the other person?

Significant Other/Date $\quad \square$ Family Member

Acquaintance

Other:

Stranger

Authority Figure

23. Was the other person involved a student?

Yes $\quad \square$ No $\quad \square$ Not sure $\square \quad \square$ Decline to answer

24. What was the gender identity of the other person?

Male $\quad \square$ Female $\quad \square$ Transgender $\quad \square$ Other

25. Where did it occur?

Own home/apartment/dorm room

The other person's home/apartment/dorm room 
At a party or social gathering

Motor vehicle

Public place, such as a street, parking lot, public park, motel/hotel, or other

Decline to answer

26. Regarding this experience, were you drinking at the time?

No

Yes, but not intoxicated

Yes, somewhat intoxicated

Yes, very intoxicated

27. Regarding this experience, was the other person drinking at the time?

No

Yes, but not intoxicated

Yes, somewhat intoxicated

Yes, very intoxicated

28. Regarding this experience, were you using recreational drugs at the time?

No

Yes, but not high

Yes, somewhat high

Yes, very high

29. Regarding this experience, was the other person using recreational drugs at the time?

\section{No}

Yes, but not high

Yes, somewhat high

Yes, very high

\section{Disclosure Questions}

30. Regarding this experience, whom did you tell?

No one

Friend or family member

Counselor, medical professional or clergy

Police or other law enforcement

University disciplinary board

More than one of the above, please list:

Other:

31. Did you make a formal report or complaint regarding this experience?

Yes

No 
No, I'm not sure what happened was a crime

$\square$ No, I was afraid of repercussions from the perpetrator

32. Have you ever attended a sexual violence prevention class, seminar or training?

$\square \quad$ No

$\square$ Yes

$\square \quad$ Not Sure

33. How would you describe your sexual orientation?

Heterosexual or straight

$\square$ Gay or lesbian

Bisexual

$\square$ Other, please specify: 


\section{Appendix D: Participant Resources}

Please print a copy of this page for your personal records.

Should you feel upset or uncomfortable after taking this survey a list of resources is

\section{provided below:}

SOU's Anonymous

Harassment, Violence, and

Interpersonal Misconduct

Reporting Form

SOU Title IX Confidential

Advisor: Angela Fleischer

SOU Student Health \&

Wellness Center

The YOU HAVE OPTIONS

Program

SOU Women's Resource Center

Ashland Police Department

www.sou.edu/health/counseling.html (counseling)

www.sou.edu/health/services.html (medical)

http://www.reportingoptions.org/

www.sou.edu/wrc/vipra.html

$541-552-6216$

911 and 541-482-

2211

SOU Campus Public Safety

www.sou.edu/security
911 and 541-552-

6258 
Appendix E: Student Email

The following email was sent to every enrolled student at Southern Oregon University on Tuesday, May 12, 2015 at 12:08pm. Embedded within the email was an anonymous survey link to the Qualtrics survey instrument.

The Southern Oregon Women's Resource Center, in partnership with Portland State University graduate student, Whitney Head-Burgess has put together a survey investigating consensual sex, unwanted sex and sexual assault among SOU students. Your participation is requested in taking this anonymous survey. The survey, based upon previous research in the field, examines disclosure of instances of consensual sex, consensual but unwanted sex and sexual assault to others, and the circumstances surrounding these incidents. Your participation is greatly appreciated. 